Article

\title{
Chemistry for Audio Heritage Preservation: A Review of Analytical Techniques for Audio Magnetic Tapes
}

\author{
Federica Bressan ${ }^{1, *(\mathbb{D}}$, Richard L. Hess ${ }^{2}\left(\mathbb{D}\right.$, Paolo Sgarbossa ${ }^{3}(\mathbb{D})$ and Roberta Bertani ${ }^{3}(\mathbb{D})$ \\ 1 Institute for Psychoacoustics and Electronic Music (IPEM), Ghent University, 9000 Ghent, Belgium \\ 2 Consultant, Audio Tape Restorer, Aurora, ON L4G 5N8, Canada; richard@richardhess.com \\ 3 Department of Industrial Engineering, University of Padua, 35131 Padua, Italy; paolo.sgarbossa@unipd.it (P.S.); \\ roberta.bertani@unipd.it (R.B.) \\ * Correspondence: federica.bressan@ugent.be; Tel.: +11-32-483-004-377
}

Received: 30 April 2019; Accepted: 21 May 2019; Published: 31 May 2019

\begin{abstract}
Vast and important cultural resources are entrusted to magnetic tape around the world, but they are susceptible to degradation, which may lead to severe replay problems. Audio magnetic tapes are complex and multicomponent devices containing organic compounds and metal systems, which can be potential catalysts for many degradative reactions in the presence of water, light, or heating. The aim of this review is to collect the literature concerning the analytical determinations and instrumental approaches that can achieve the chemical identification of the components in the tape and the degradation state. Thus, a combination of destructive (such as acetone extraction) and non-destructive techniques (such as ATR FTIR spectroscopy) have been proposed, together with SEM, ESEM, XRD and TGA analyses to assess the chemical and physical characterization of the tape with the purpose to individualize restoration treatments and optimize conditions for preservation. The impact of the studies reviewed in this paper may go beyond audio, being potentially relevant to video, data, instrumentation, and logging tapes.
\end{abstract}

Keywords: magnetic audio tape degradation; magnetic audio tape restoration; magnetic audio tape preservation; spectroscopic techniques such as FTIR and XRD; electron microscopy determinations

\section{Introduction}

Analog magnetic audio tape recording was first proposed in 1878 and became a practical product in 1935. From 1947, it was the primary method of audio recording until challenged by digital recording (often still relying on magnetic tape) in the 1980s. It also influenced information storage in multiple environments as the technologies originally designed for audio were adapted to other uses ${ }^{1}$ [1]. Vast and important cultural resources are entrusted to magnetic tape around the world. In 2001, Dr. Dietrich Schüller defined the challenge, "The world's stock of audio recordings is estimated to be more than $50 \mathrm{Mh}$ (million hours) of materials... unique memorable and non-repeatable events, but also traditional and folkloristic music, as well as other bio-acoustic [material, and material of oral tradition, given its scientific, cultural, historical, juridical, social, and economic value. None of these recordings are on permanent carriers..." [2]. It is this

1 [a] Engel, F.K. (ed.), “Oberlin Smith and the Invention of Magnetic Sound Recording [a] An Appreciation on the 150th Anniversary of the Inventor's Birth", 1990, revised version 2006. Full text available online: http:/ / bit.ly / oberlin2006 (last visited 24 April 2019); [b] Engel F. and Hammar, P., "A Selected History of Magnetic Recording. by Friedrich Engel and Peter Hammar; additional editing by Hess R.L. in 2006. Full text available online: http:/ / bit.ly/engels2006 (last visited 24 April 2019). 
challenge that informs the present study. In 2008, Hess attempted a review of the broad range of factors affecting tape life (Figure 1) [3]. A webpage collects reports from the field to keep the 2008 paper updated ${ }^{2}$.

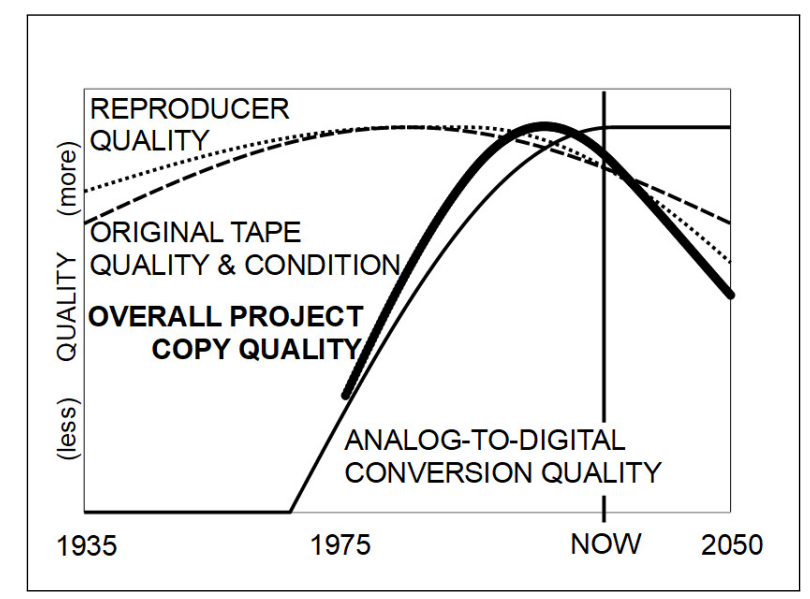

Figure 1. Conceptual time line of restoration quality.

There are many factors that complicate any chemical analysis of tape degradation. A primary consideration is that a tape is not a single homogeneous object (with the exception of some early German tapes during 1943-1954 that included the magnetic particles embedded in a Polyvinylchloride (PVC) substrate). The vast majority of tapes are made with at least a base-film layer and a coating that holds the magnetic particles on one face of the tape (mag coat). In the late 1960s, tapes with a third coating, on the face opposite the mag coat, came into prominence for high-end mastering uses. This back coat improved the winding of the tape and also was conductive, reducing static electricity charges.

Prior to the widespread use of tape as we know it today, both steel tapes and wires were used for magnetic recording. The first coated tape was introduced in 1935 in Germany with an acetate base. In 1943, an industrial accident destroyed the IG Farben tape manufacturing plant that made the acetate tape. The experimental homogeneous PVC tape was brought on line and was the mainstay into $1946^{3}$. As the tape technology was brought to the United States by Mullin, Ranger, Orr, and others, Orr and Minnesota Mining and Manufacturing (3M) began making tape. Orr was ordered by General Eisenhower to provide American made tape for the Allies' use after incomplete erasure of a German tape had Eisenhower's and Hitler's voices mixed in a broadcast. 3M's first tape was on a paper base in 1947, but type 111 was introduced on an acetate base film in 1948 and was produced for about 25 years ${ }^{4}$.

Audio tape is generally made with either acetate (note that $3 \mathrm{M}$ refers to this as "plastic") or Polyethylene terephthalate (PET) base films Mylar, Tenzar, Polyester, etc.), with small quantities of paper

2 Hess, R.L. "-Degrading Tapes", 2018. Link: http://bit.ly/DegradingTapes (last visited 24 April 2019). Other resources for basic restoration information include: [a] Copeland, A., "Manual of Analogue Sound Restoration Techniques", The British Library, 2008. Full text available online: http://bit.ly/copland2008 (last visited 24 April 2019); [b] IASA 2014-2017, https:/ / www.iasa-web.org/iasa-special-and-technical-publications (last visited 24 April 2019); [c] Marques 2014, https:/ / www.loc.gov/folklife/sos / preserve1.html (last visited 24 April 2019).

3 For an overview of Agfa, BASF, and IG Farben's tapes production, see: http:/ / bit.ly/locHeritage (last visited 24 April 2019). Some of this history is discussed in: Engel F. and Hammar, P., "A Selected History of Magnetic Recording" additional editing by Hess R.L. in 2006. Full text available online: http:/ / bit.ly/ engels2006 (last visited 26 April 2019).

4 For an overview of 3M's tape manufacturing history, see: http://www.aes.org/aeshc/docs/3mtape/aorprod-si.pdf (last visited 25 April 2019). 
and PVC (both homogeneous and coated) also used early on. While not employed for analog audio tapes, some video and data tapes use a Polyethylene naphthalate (PEN) base film.

While the long-term stability of the base film is obviously very important, many of the degradations appear to occur in one or both of the coatings or the interaction between the two coatings. To a lesser extent, the adhesion of the coating to the base film may reduce tape life, and some acetate based tape has base film degradation issues. The major failure modes for PET based tape appear to be mag coat degradation. The influence of the back coat on that degradation (or the degradation of the back coat) is still not fully understood. Richardson persistently advances his theory that the back coat alone is the bad actor and that, after its removal, tape life is extended [4]. The process has been patented [5], but there appears to be no commercial operation regularly performing this restoration technique.

\subsection{Challenges}

The challenges to any successful study is that current tape archives date back to the late 1940s (only a small portion of tapes pre-date that) and many of the degradations do not become problematic until many years after the tape was manufactured. Several factors were discussed at the June 2018 AES International Conference on Audio Archiving, Preservation \& Restoration held at the Library of Congress Packard Campus in Culpeper, Virginia. There seemed to be some consensus that the challenges affecting the research into the chemical breakdowns are many, including:

- $\quad$ Original formulations were and are considered trade secrets

- Audio tapes are rarely marked on the tape as to manufacturer and type

- Audio tapes often are placed in different boxes than they came in

- There were running changes during production

- $\quad$ There were process control variations

- $\quad$ There were different storage conditions

The first three points create confusion as to the manufacturer and type of any tape being studied. While one might assume that analysis such as FTIR can uniquely identify a particular tape, the last three points challenge this possibility. As Hess [3] pointed out:

Benoît Thiébaut, in his presentation to the 2005 AMIA conference, indicated that he had found a range of video cassettes with the same type designation comprised of four clearly different chemical formulations [6]. In discussing this result with Bob Perry ${ }^{5}$, he stated that one would never see this much variation in a particular type number during the time he was at Ampex (1969-1992). Scotch/3M was open about the variations in type $111^{6}$. Bradshaw indicated ${ }^{7}$ that aging could possibly create some of the differences found by Thiébaut and that additional analysis would be beneficial. He also indicated the potential for seasonal changes and the difficulties of moving a successful tape line from one climatic location to another. Outsourcing further complicates this analysis, as the box may have one brand on it and the tape may have been manufactured at another facility.

5 Personal communication with Bob Perry, former Director of Advanced Development in the Magnetic Tape Division of Ampex Corporation, 29 July 2006.

6 Further confirmation of running changes can be found in the online copies of the Scotch/3M Sound Talk publications, numbers 13-20-21-22. Available online: http:/ / www.aes.org/aeshc/docs/3mtape/soundtalkindex.html (last visited 24 April 2019).

7 Personal communication with Dr. Richard Bradshaw, Tape Development, IBM Tucson, AZ, USA, 31 July 2006 . Note that Bradshaw was the person who finally was able to safely unspool the Challenger tape after it was recovered from the ocean floor. He also led the team developing the IBM 3480 and 3490 data tapes, which have (so far) an enviable record of longevity and stability. 


\subsection{Goals}

One of the oft-stated goals of research into tape degradation is to provide a toolkit to easily and inexpensively categorize the current condition of the tape and its likelihood to degrade in the near term, thus prioritizing making a digital preservation copy.

A second goal is, if degradation is observed, to suggest the correct method of treating the tape prior to making a digital preservation copy. This is important because treatments that can benefit one type of tape may damage another.

As outlined in the previous section, even if the tapes were slit from the same "jumbo" roll, there are factors which could result in tapes behaving differently after years of storage, thus any proposed tests need to be sensitive to the current condition. Figure 2 shows a typical analog audio tape machine.

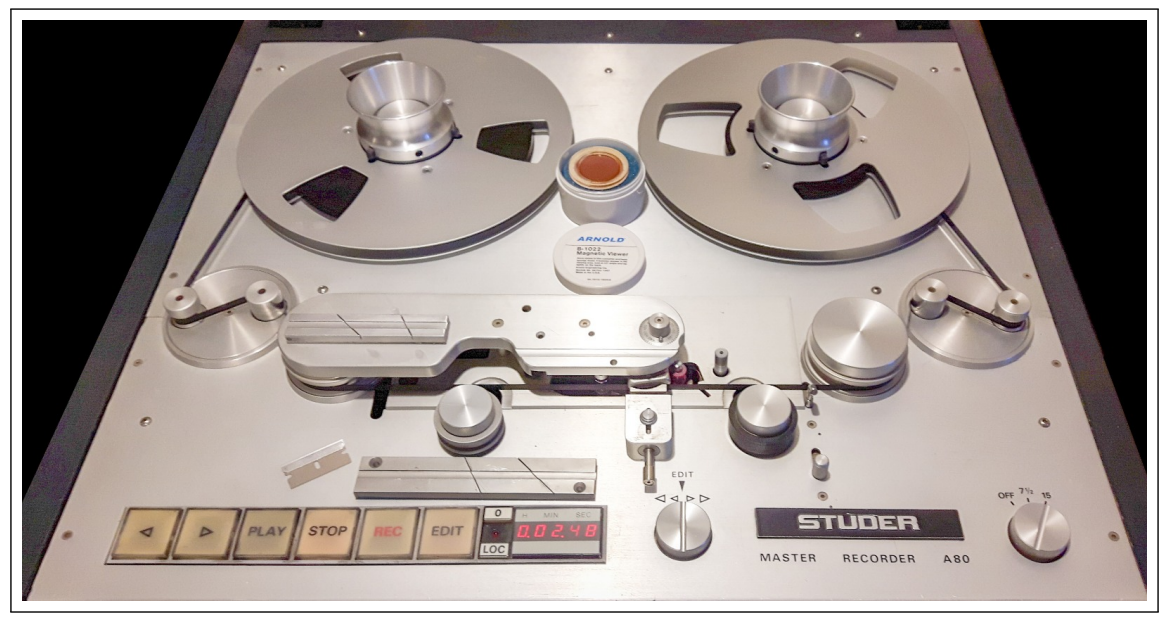

Figure 2. Studer A80-RC tape machine with an Arnold B-1022 Magnetic viewer at the ready and an EdiTall splicing block.

\subsection{Related Fields}

While this paper discusses studies focusing mostly on audio tapes, it is important to realize that collections may hold a mix of tapes which may appear similar but are separated by a variety of factors. Sometimes it is not easy to determine which category a tape falls into due to their visual similarities. While this is in no way an exhaustive list, it is a first pass at separating the different branches of tape recording as it evolved, which should be informative to those curating magnetic tape cultural heritage. Conversely, studies from other branches can also inform decisions for audio tape.

As stated previously, audio recording on magnetic tape began in 1935 and grew slowly due to many factors, not the least of which was World War II. However, by the end of the 1940s/early 1950s, it was exploding. Between about 1950 and about 1960, what started as analog audio magnetic tape split into five major branches (including audio). It is often convenient to address these four additional branches separately, as they morphed to do different jobs.

\subsubsection{Data Tape}

Stacks of Hollerith (later IBM) punched cards were the normal way of storing data in 1950. The Hollerith cards were patented in 1889 [7]. Hess recalls a summer job in 1968 where they were still being used. By 1952, IBM had delivered the first modern data tape drive. This was a fully implemented drive, complete with vacuum columns (the equivalent to tension arms on an audio machine, and implemented on 
a few high-end video machines) to allow rapid tape acceleration under program control. These machines recorded seven (later nine) tracks on $12.7 \mathrm{~mm}$ (half-inch) tape on $270 \mathrm{~mm}$ (10.5 in) reels [8], although their hubs were incompatible with the familiar NAB audio tape hub ${ }^{8}$ [9].

In the 1980s, data tape migrated to mostly single-reel cartridges that were able to be utilized in robotic library systems. This remains how vast amounts of data are stored in many operations. IBM originally had their data tapes manufactured by the audio tape manufacturers, but found they needed better quality control [8].

\subsubsection{Instrumentation Tape}

Instrumentation tape was developed as a spinoff of audio tape for recording signals for the United States Air Force in the early 1950s. These signals were telemetry from test flights. The Inter-Range Instrumentation Group (IRIG) has been developing standardized telemetry requirements since the mid-1950s. Instrumentation tapes became widely utilized outside of aerospace and can be found recording signals from seismometers, vibration and other sensors in structural and machine engineering, and bio-medical research [10]. For example, all the telemetry, including the low-scan-rate video, from the moon landing in 1969 was recorded on 14-track $25.4 \mathrm{~mm}$ instrumentation tape. Alas, those tapes of the moon landing were not preserved, and only lower quality scan converted broadcast signals were retained ${ }^{9}$.

IRIG instrumentation tapes look like audio tapes. The reels are the same; the tape width is generally $12.7 \mathrm{~mm}$ or $25.4 \mathrm{~mm}$. The speeds look familiar to audio users, but contain a wider range, generally between $11.9 \mathrm{~mm} / \mathrm{s}(15 / 32 \mathrm{in} / \mathrm{s})$ and $6.1 \mathrm{~m} / \mathrm{s}(240 \mathrm{in} / \mathrm{s})$. The equalization is such that the speed can be slowed down or sped up at will without changing the relative response. The common track counts are 7, 14, and 28 tracks. Frequency modulation (FM) recording is part of the standard, extending the low frequency response to DC. Many of the failure modes found in audio tape exist in instrumentation tape. Instrumentation tape is an analog recording while data tape is a digital recording.

\subsubsection{Video Tape}

In 1956, Ampex introduced the first professional video tape recorder, the VR-1000. It used $50.8 \mathrm{~mm}$ (two-inch) tape and recorded tracks across the width of the tape via a spinning head. Because of the four heads on the rotating headwheel $(14,400 \mathrm{rpm})$, it was called the quadruplex system. This format was still being used in 1990 at some smaller market TV stations. The second major format in North America (and elsewhere) was the SMPTE Type C helical format which used $25.4 \mathrm{~mm}$ (one-inch) open reel tape. These video tape reels had the standard NAB hub designs.

There have been over 100 different video tape formats, and the reference attempts to list them all along with their salient characteristics. Obviously, recovery of video tapes is a whole different art from audio with its own set of challenges and failure modes, but many of the same basic tape-oriented problems are similar ${ }^{10}$.

8 This is the actual 1965 NAB standard that includes the physical details of the NAB hub: http:/ / bit.ly/nabHess (last visited on 27 April 2019).

9 See article published on Reuters: Fox, M., "Moon landing tapes got erased, NASA admits," 16 July 2009. Full text online: http:/ / bit.ly/eraseMoon (last visited 24 April 2019).

10 See Tim Stoffel's webpage "Museum of Broadcast Technology" on Quadruplex Park Videotape Formats: http:/ / www.lionlamb. us/quadpark.html (last visited on 25 April 2019). 


\subsubsection{Logging Tape}

Logging tapes are really audio tapes, except, they will not play on normal audio tape machines. These tapes are on $270 \mathrm{~mm}$ (10.5 in) NAB standard audio reels and are generally 12.7 or $25.4 \mathrm{~mm}$ in width. Tape length per reel is $1100 \mathrm{~m}$ (3600 ft.) and, with the tape running at $11.9 \mathrm{~mm} / \mathrm{s}(15 / 32 \mathrm{in} / \mathrm{s})$ provides over $25 \mathrm{~h}$ of recording allowing continuous recording with one tape per day with reasonable overlap with two recorders. The bigger challenge is that a typical logging tape may contain 40 or more channels/tracks on a $25.4 \mathrm{~mm}$ wide tape, plus a time code channel. One tape could hold $960 \mathrm{~h}$ of material $(24 \mathrm{~h} \times 40$ tracks). This is a very obscure area of recording but is worth mentioning as logging tapes do show up in archives.

\subsubsection{Beyond Reels}

There is roughly a 30-year period from approximately 1980 to 2010 where a stupendous variety of dedicated formats were designed for audio, data, instrumentation, video, and logging purposes, and the reel-to-reel machines were replaced. Many of these players had special features that are not easy to replicate. While many of the tape degradation factors apply to these later tapes, finding working reproducers for recordings made roughly between 1980 and 2010 is a far bigger challenge than the tape degradation at this point. In audio, DAT is far more at risk than open reel analog.

The analysis and remediation of tape failure modes are an important part of the work in an archive, however, the tape is only part of a system, and the availability and viability of the entire system is required to recover the content entrusted to the tapes.

Many projects have been promoted and carried out around the world to preserve the magnetic archives [11].

Examples are the PrestoSpace project [6] and the FACET project [12]. PrestoSpace involved a significant amount of chemical research and attempted to map out how much European audiovisual material might be lost by 2015 (the prediction was 40\%). The FACET project was a survey and assessment tool which looked at individual collections within larger archives at Indiana University and scored them based on their long-term risk of deterioration. After completing a portion of the survey, Indiana University was convinced to start an organized, all-inclusive media digitization process ${ }^{11}$.

Different perspectives are involved in a preservation project: (a) the digitization of the formats which would be realized within 15-20 years not to lose information due to deterioration of tapes, even if the amount of material is enormous [13,14]; (b) the disclosure of archives (taking into account also legal implications); and (c) the preservation of the tape as objects themselves $[15,16]$.

Over time, great attention has been paid to the restoration of video tapes and data archives with the objective to digitize them, while much less interest and studies have been devoted to the restoration and preservation of audio material.

The aim of this paper is to review the scientific literature (academic and professional, including patents) concerning the analytical methods to identify tape formulations in terms of chemical components, the typology and origin of the degradation processes [3], and the known and applied remediation methods.

\section{Composition of Magnetic Tapes for Audio Data Storage}

Starting from the historical paper strips with iron particles, a search to improve the performance of magnetic recording tapes was carried out to increase the recording density, coercitivity, and mechanical

11 Website of the Indiana University's Media Digitization \& Preservation Initiative: https://mdpi.iu.edu/ (last visited on 24 April 2019). 
properties according to the tape player technology [17-19]. For example, when video tape was introduced in 1956, the popular acetate tape would not sustain the high head rotation velocity. New tape formulations were required and PET-based tapes were used from 1956 forward for video recording.

The structure of magnetic tapes is shown in Figure 3. The tapes considered to be inherently stable by JASA and which should be copied are: Standard play tapes $(36-38 \mu \mathrm{m}$ base film with about $52 \mu \mathrm{m}$ total thickness), Long play tapes (24-25 $\mu \mathrm{m}$ base film with about $35 \mu \mathrm{m}$ total thickness), Double play tapes (12-13 $\mu \mathrm{m}$ base film with about $26 \mu \mathrm{m}$ total thickness) and triple play tapes (12-13 $\mu \mathrm{m}$ base film with about $18 \mu \mathrm{m}$ total thickness). It is worth noting that thin film (evaporated) tapes have not been used in audio, and are most widely used in data storage.

It was calculated that magnetic recording tapes consist of approximately $20 \%$ by weight of magnetic material (metal oxide or metal particles) and remaining $80 \%$ wt of polymeric material. The composition by volume is about $40 \%$ magnetic material, $40 \%$ polymers, and $20 \%$ minute pores (responsible for noise), which are necessary to prevent adhesion of the tape surface to the recording head of any playback equipment.

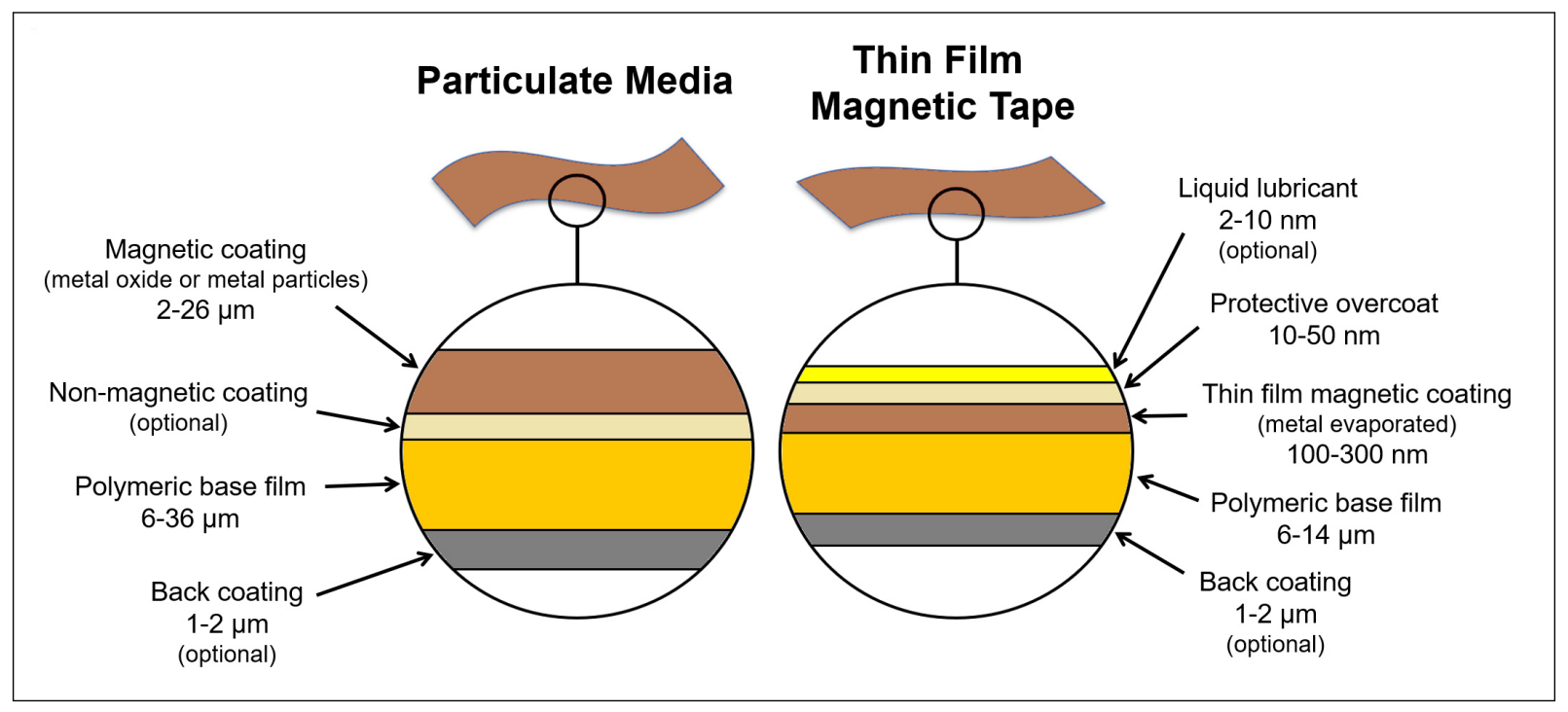

Figure 3. Scheme of the structure of audio magnetic tapes.

(A) The polymeric base film, which provides the mechanical properties and is responsible for the physical integrity of the tape, is a polymeric material that has been of different nature during the time [20], as shown in Figures 4-7.

Cellulose diacetate polymer was used from the beginning of 20th century until about 1940, when it was substituted by the completely acetylated derivative, which is more thermally and chemically resistant than the diacetate. From 1943, in particular by BASF, PVC was used. Pure it is rigid, but can be made softer and more flexible by the addition of plasticizers, the most widely used being phtalates. Typical characteristics of PVC are high hardness and good mechanical properties; poor heat stability but good flame retardancy; and chemical resistance to acids, salts, bases, fats, and alcohols. Some solvents may only swell it but not dissolve it, but some, such tetrahydrofuran or acetone, may damage it. Very thin paper, which he coated with iron oxide powder using lacquer as glue, was used by Pfleumer (1881-1945) in 1928 to patent the first magnetic tape. Cellulose, the major constituent of paper, is a material chemically stable, but fragile and subject to tearing or breaking upon playback. From 1953, PET was used for its good chemical and mechanical properties sometimes substituted by polyethylene naphthalate with strength and 
modulus, chemical and hydrolytic resistance, gaseous barrier, thermal and thermo-oxidative resistance, and ultraviolet light barrier resistance higher than PET.

a)

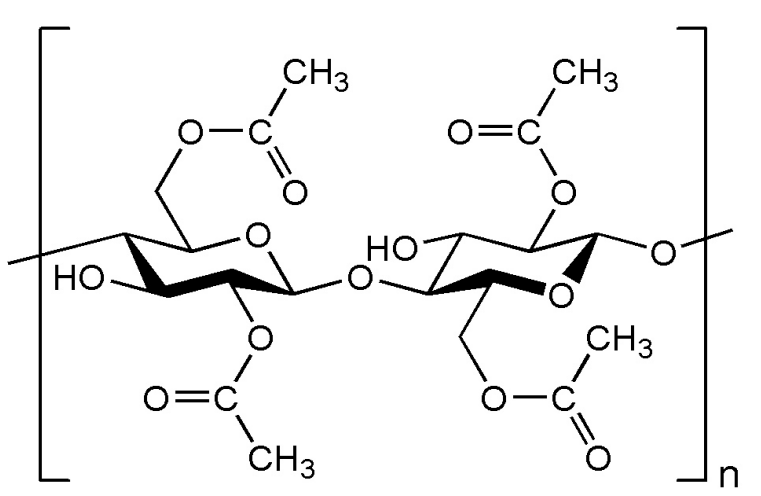

b)

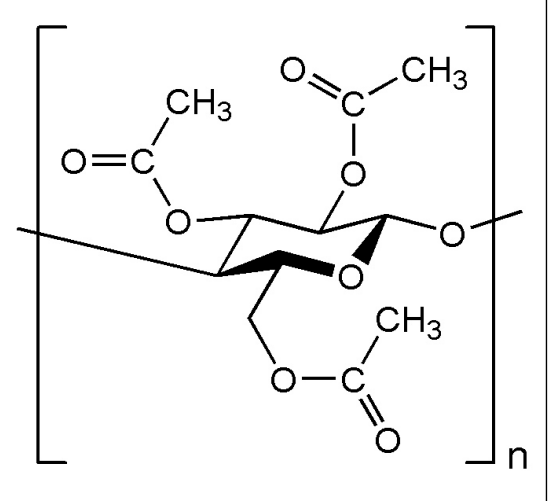

Figure 4. (a) Cellulose acetate (used from 1935 to1972/73; examples: Ampex 611 and Scotch 111), hydrophilic and soluble in many common solvents; and (b) cellulose triacetate (CAS number 9012-09-3).

a)

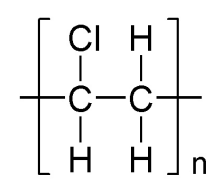

b)

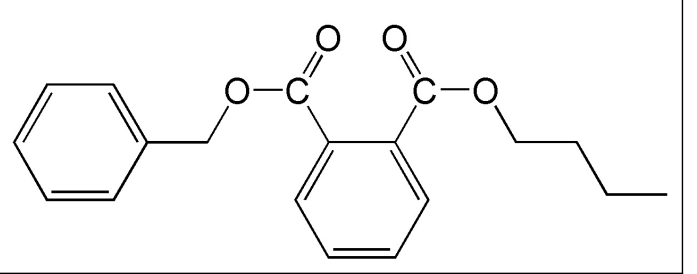

Figure 5. (a) Polyvinyl chloride (PVC) (CAS number 9002-86-2; used from 1943-1969; manufactured particularly by BASF); and (b) benzyl butyl phthalate (BBP), one of the most used plasticizer for PVC.

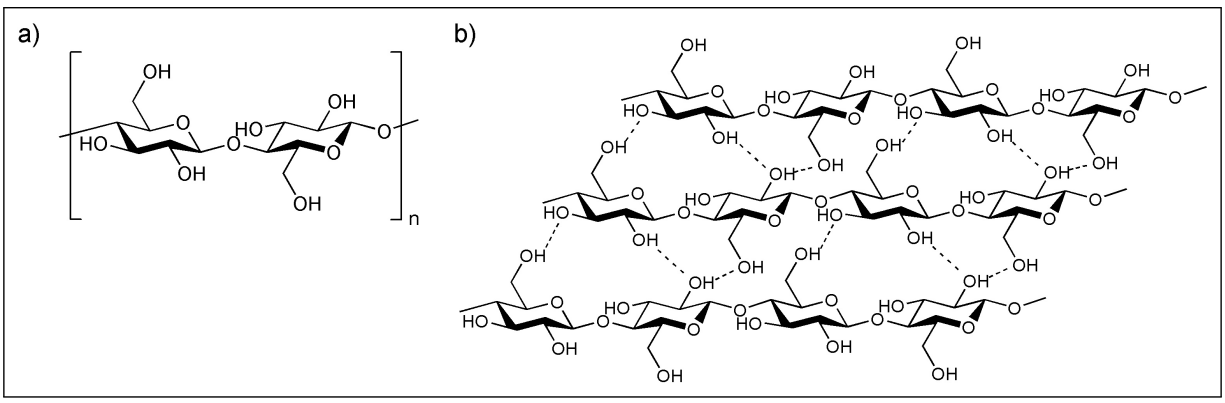

Figure 6. Paper (used from 1947 to 1953; examples are Scotch 100 and 101): (a) Cellulose, the major constituent of paper; and (b) a strand of cellulose where hydrogen bonds bind cellulose molecules.

a)

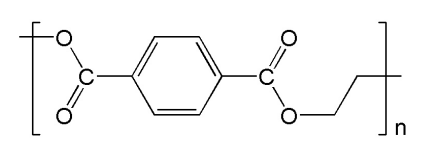

b)

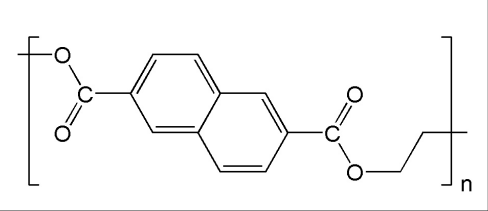

Figure 7. (a) Polyethylene terephthalate (PET) (used from 1953, it is the only one in use; an example is Scotch 102); and (b) polyethylene naphthalate (PEN). 
(B) The binders containing the magnetic particles (in particulate media) are typically polyester-polyurethane materials (PE-PU). The enormous number of formulations (different $n$ and $\mathrm{m}$ values in Figure 8) give different polymers with specific chemical, physical, and mechanical properties [21-23] The amount of binder must be as low as possible, but sufficient to bind the high quantity of metal particles. It contains a hard part, given by the polyurethane chain (with high $\mathrm{Tg}$, sometimes crystalline), and a soft one (with relatively low $\mathrm{Tg}$ ), the polyester. The relative amount of soft and hard microphases, the degree to which they can separate and the resulting morphology have a strong effect on the copolymer's ultimate properties and ageing [24].

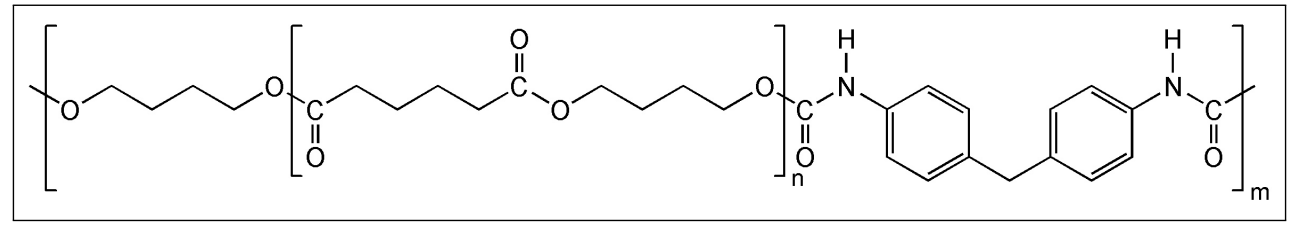

Figure 8. The structure of polyester-polyurethane materials.

In addition, polyurethane/polyisocianate as binders, and for certain products also cobinders (such as PVC or phenoxyresins), have been used. Isocyanate moieties are very sensitive to moisture: with water, the formation of an interpenetrating polyurea in the polyurethane matrix can occur [25]. The need of high density recording required using higher magnetization retentive Co-epitaxial, $\gamma-\mathrm{Fe}_{2} \mathrm{O}_{3}$ powder or $\alpha$-Fe powder in place of conventional $\gamma-\mathrm{Fe}_{2} \mathrm{O}_{3}$. Thus, the interfacial properties between the magnetic powder and the binder polymers had to be improved, being good dispersion, high packing and high orientation of acicular magnetic particles important factors. It was reported that a small amount of active functional groups in polymers improved the dispensability of $\gamma-\mathrm{Fe}_{2} \mathrm{O}_{3}$ and the magnetic properties of the magnetic tapes, anchoring the particles to the surface. The order of interaction force of the functional groups to $\gamma-\mathrm{Fe}_{2} \mathrm{O}_{3}$ was the following $[26-30]^{12}$.)

$$
-\mathrm{PO}_{3} \mathrm{H}_{2}>-\mathrm{SO}_{3} \mathrm{H}_{2}>-\mathrm{COOH}>-\mathrm{OH}>\text { epoxy moiety }>-\mathrm{CN}
$$

(C) Magnetic particles: The most common particles are $\gamma-\mathrm{Fe}_{2} \mathrm{O}_{3}\left(\mathrm{Hc} 250 \mathrm{Oe}^{13}\right), \mathrm{CrO}_{2}$ and Co-doped $\gamma-\mathrm{Fe}_{2} \mathrm{O}_{3}$ ( $\mathrm{Hc} 600 \mathrm{Oe}$ ) increasing both the regenerative output and recording density. $\mathrm{CrO}_{2}$ provides higher signal output than $\mathrm{Fe}_{2} \mathrm{O}_{3}$, but it is harmful to the polymer being an oxidant. To achieve high density recording applications, magnetic particles made from Barium ferrite particles, iron alloyed with Cobalt and Nickel have been used (in particular for data storage). Higher concentration of magnetic material in a given binder volume allows higher coactivity and magnetization [31]. The magnetic layer also contains lubricants (fatty acid esters) and small amounts of pigments as abrasives $\left(\mathrm{Al}_{2} \mathrm{O}_{3}\right.$ or $\left.\mathrm{SiO}_{2}\right)$ which can cause damage to magnetic heads [32]. Metal magnetic powder was also widely employed instead of oxide magnetic powder to improve the performance further with Hc of about 1500 Oe [33]. Metal iron particles can give oxidation, forming oxides, hydroxides or oxide-hydroxides (collectively referred, usually, as iron oxides) which consist of close packed arrays of $\mathrm{O}_{2}{ }^{-}$anions in which the interstices are partly filled with $\mathrm{Fe}^{\mathrm{II}}$ or $\mathrm{Fe}^{\mathrm{III}}$ in octahedral $\left(\mathrm{Fe}(\mathrm{O}, \mathrm{OH})_{6}\right)$ or tetrahedral $\left(\mathrm{FeO}_{4}\right)$ coordination. The various oxides differ in the way the basic structure units- $\mathrm{Fe}(\mathrm{O}, \mathrm{OH})_{6}$ or $\mathrm{FeO}_{4}$-are arranged in the space.

12 The use of polyurethane appears to be the primary direction tape manufacturing went around the time this patent was issued, i.e., the mid-1970s.

$13 \mathrm{Oe}=$ Oersted; unit of magnetic field strength in CGS system. $1 \mathrm{Oe}=(1000 / \mathrm{B})(\mathrm{A} / \mathrm{m})$. In vacuum, if the magnetic field strength $\mathrm{H}$ is 1 Oe, the magnetic field density $\mathrm{B}$ is 1 Gauss. In a medium having permeability $\mu, \mathrm{B}(\mathrm{Gauss})={ }^{-} \mathrm{H}(\mathrm{Oe})$. 
The most common oxides, and present in nature, are goethite $\alpha$-FeOOH (the most thermodynamically stable at ambient temperature and, therefore, the first to form or the end member of many transformations, yellow brown, orthorombic structure, antiferromagnetic, $\mathrm{d}=4.26 \mathrm{~g} \mathrm{~cm}^{-3}$ ), lepidocrocite $\gamma$-FeOOH (orange colored, orthorombic structure, antiferromagnetic, $\mathrm{d}=4.09 \mathrm{~g} \mathrm{~cm}^{-3}$ ) and hematite $\alpha-\mathrm{Fe}_{2} \mathrm{O}_{3}$ (blood-red colored or black if finely divided, rombohedral hexagonal structure, weakly ferromagnetic or antiferromagnetic, $\mathrm{d}=5.26 \mathrm{~g} \mathrm{~cm}^{-3}$ ).

The most important iron magnetic oxides [34-37] are magnetite $\left(\mathrm{Fe}_{3} \mathrm{O}_{4}\right)$ and maghemite $\left(\gamma-\mathrm{Fe}_{2} \mathrm{O}_{3}\right)$, as shown in Figure 9. Magnetite is a black ferrimagnetic oxide containing both $\mathrm{Fe}^{\mathrm{II}}$ and $\mathrm{Fe}^{\mathrm{III}}$ ions forming two interpenetrating magnetic sublattices: $\mathrm{Fe}^{\mathrm{III}}$ occupies tetrahedral sites and octahedral sites are occupied by both $\mathrm{Fe}^{\mathrm{II}}$ and $\mathrm{Fe} \mathrm{III}^{\mathrm{II}}$. Thus, the structure consists of octahedral and mixed tetrahedral/octahedral layers stacked along [111] direction. Below the Curie temperature $(850 \mathrm{~K})$, the spins of the tetrahedral and octahedral sites are antiparallel and have unequal magnitude: this causes ferrimagnetism (Figure 10). The spin arrangement is written as $\mathrm{Fe}^{3+}\left[\mathrm{Fe}^{3+} \mathrm{Fe}^{2+}\right] \mathrm{O}_{4}$. By controlling the particle size and morphology, magnetites with coercitivity ranging from 30 to 250 Oe can be produced. Particles smaller than $6 \mathrm{~nm}$ are super-paramagnetic at room temperature. If particle size of crystal is similar, coercitivity goes from spheres < cubes < octahedra according to the number of magnetic axes along these shapes. Maghemite occurs as a weathering product of magnetite and resembles magnetite in structure and magnetic properties. It is a red-brown ferrimagnetic oxide isostructural with magnetite but with cation deficient sites. The structure consists of two sublattices corresponding to $\mathrm{Fe}^{\mathrm{III}}$ located on tetrahedral and octahedral sites, cationic vacancies compensate for the oxidation of $\mathrm{Fe}^{2+}$ maintaining charge neutrality. Maghemite has a cubic unit cell, each containing $32 \mathrm{O}^{2-}$ ions, $64 / 3 \mathrm{Fe}^{\mathrm{III}}$ in both tetrahedral and octahedral sites (Figure 9) and $40 / 3$ vacancies in octahedral sites. Measurement of Curie temperature is difficult because maghemite transforms to hematite $\left(\alpha-\mathrm{Fe}_{2} \mathrm{O}_{3}\right)$ at temperatures above $700-800 \mathrm{~K}$ (TC has been estimated in the range 820-986 K) [38].

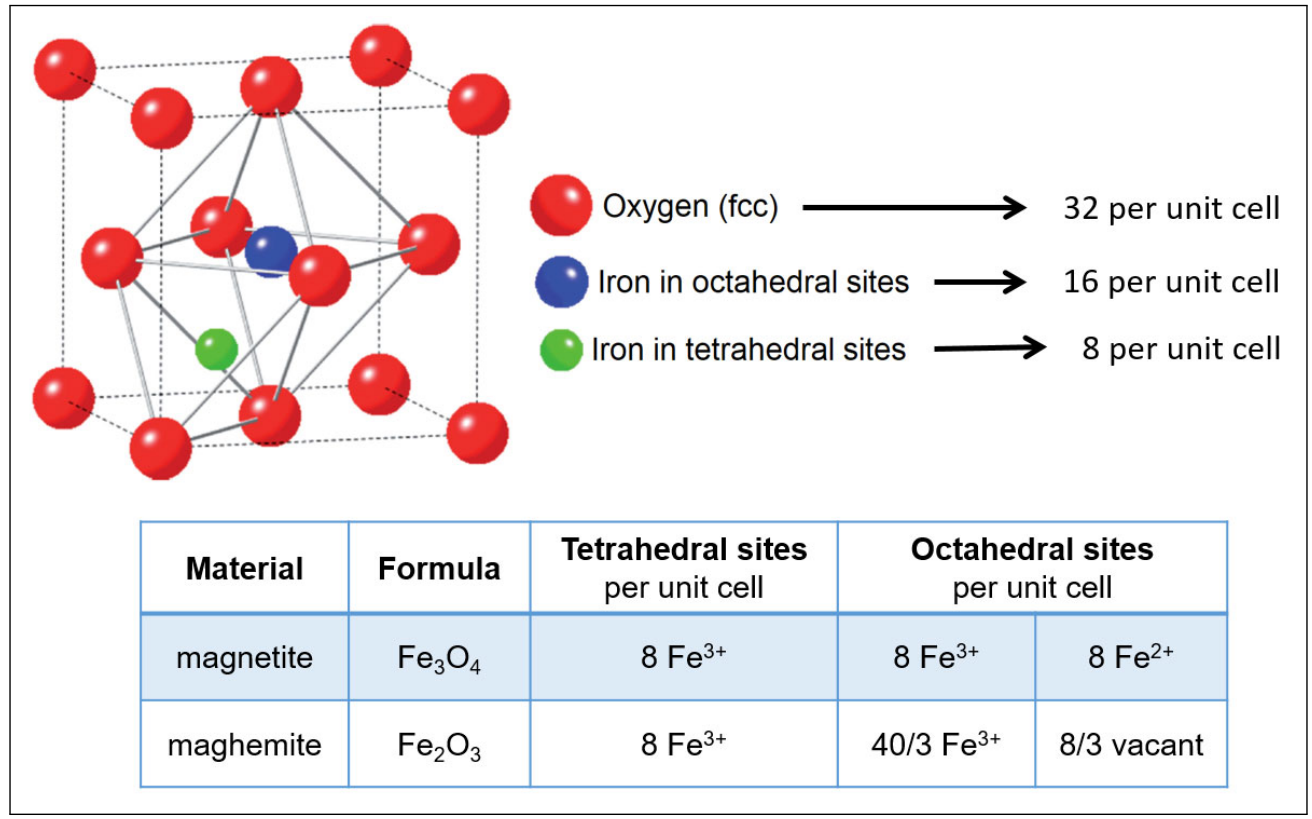

Figure 9. Structural information on the spinel structure of magnetite $\left(\mathrm{Fe}_{3} \mathrm{O}_{4}\right)$ and maghemite $\left(\mathrm{g}-\mathrm{Fe}_{2} \mathrm{O}_{3}\right)$.

(D) Back coating, with a typical thickness of 1-3 $\mu \mathrm{m}$, provides good tape packing as the rough surface allows air to escape and since it is conductive it aids in dissipating the static charge accumulated during 
playing and rewinding. It contains carbon black (providing conductivity to drain electrostatic charges from the tape) in a PE-PU binder. It also imparts a certain amount of friction to the smooth carrier foil to facilitate improved winding characteristics.

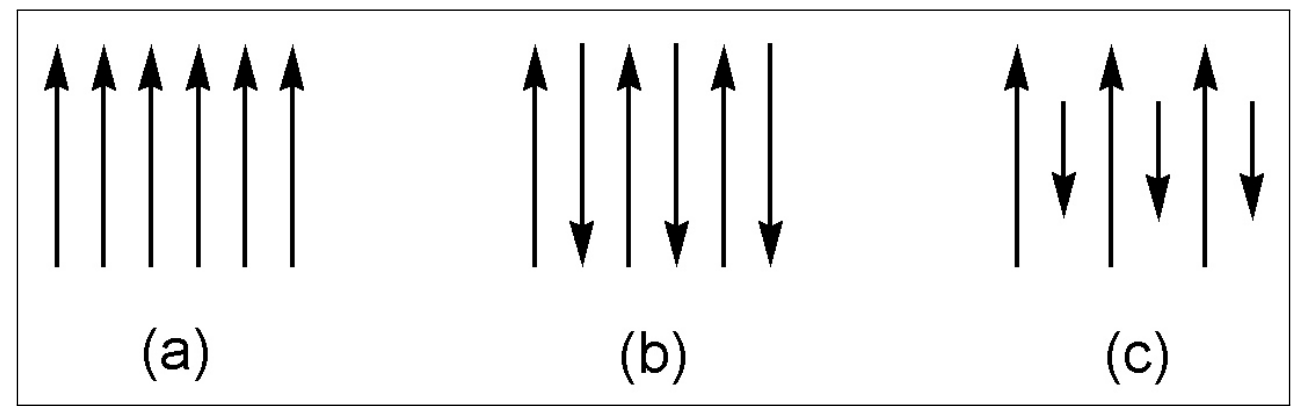

Figure 10. Arrangement of magnetic dipoles for different types of magnetism: (a) ferromagnetism; (b) antiferromagnetism; and (c) ferrimagnetism.

(E) Lubricants: They can be of different chemical nature, in particular fatty acids (more widely used myristic, lauric, palmitic, and stearic ones (Table 1); ester of fatty acids (including butyl, pentyl, isopropyl, and isobutyl derivatives); paraffinic oils (i.e., linear alkanes such as squalanes); and silicones and fluorinated lubricants have been used. Silicones, of general formula $\left[\mathrm{R}_{2} \mathrm{SiO}\right] \mathrm{n}$ (where $\mathrm{R}$ is an alkyl or an aryl group), consist of an inorganic silicon-oxygen backbone chain (-Si-O-Si-O-Si-O-) with organic side groups attached to the tetravalent silicon atoms. Fluorinated lubricants are fluorocarbon-ether polymers of polyhexafluoropropylene oxide (PFPE). An example is Krytox ${ }^{(R)}$ working in the range from -90 to $+450{ }^{\circ} \mathrm{C}$. It is chemically inert and does not burn. Synthesized perfluoropolyethers (PFPE) allow not only to have large coverage ratio of the outer most surface by lubricant but also a sufficient amount of sub-surface lubricant. It was also observed that the friction coefficients increased with increasing storage days because the polar lubricant is absorbed with magnetic particles and does not migrate easily to the surface [39-45]. 
Table 1. Some different compounds which are generally used as lubricants in magnetic audio tapes:

(a) silicones; and (b) fluorocarbon-ether polymers of polyhexafluoropropylene oxide (PFPE).

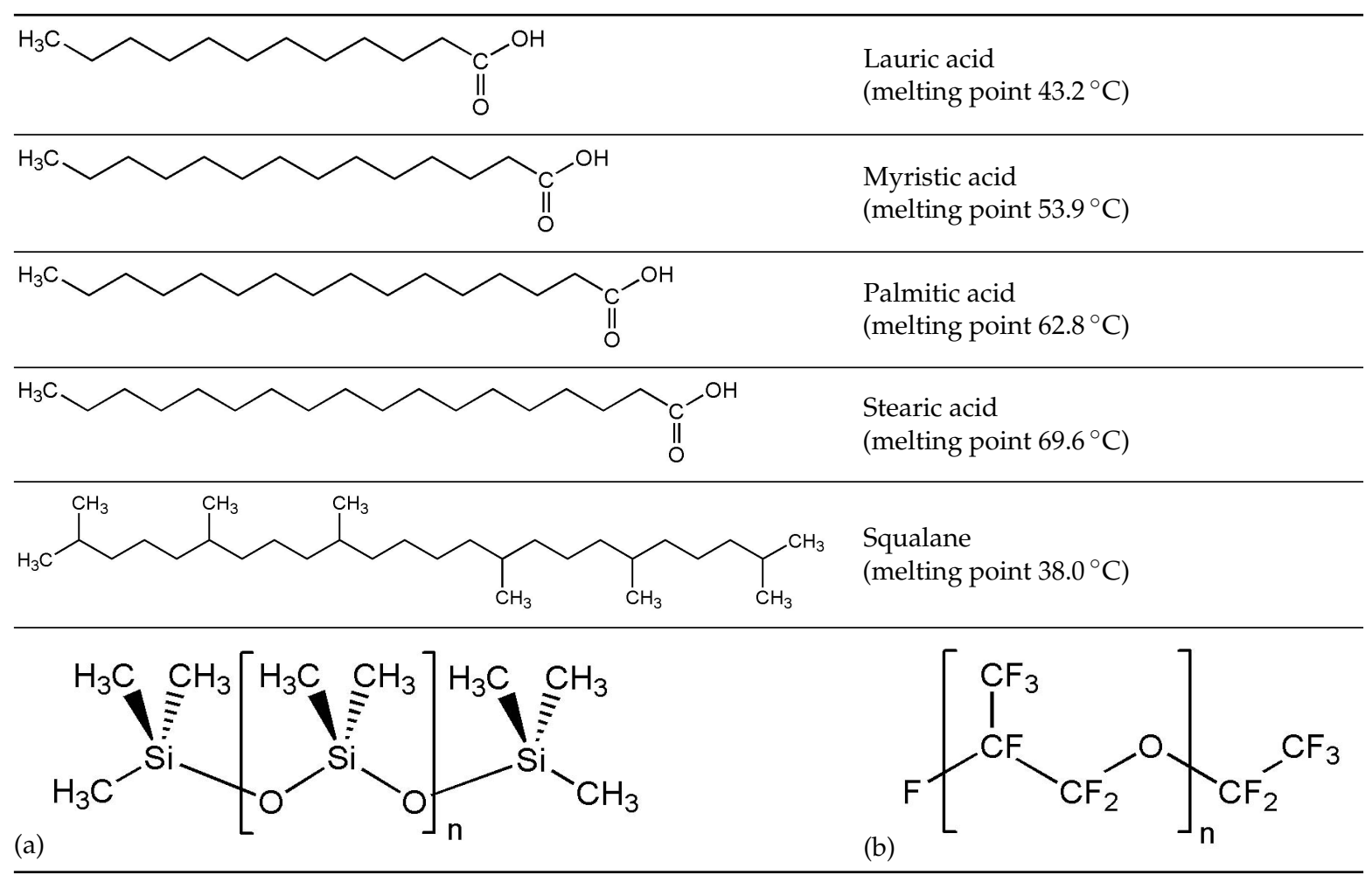

To reduce friction between guide and magnetic tape, a novel approach has been proposed by laser surface texturing giving the formation of an air bearing foil [46]. Advanced ultra-high density tapes (usually of PET or PEN) require minimal friction being in contact or near contact with the recording head at high relative velocities. New materials for thin film tapes (aramid systems) and for heads $\left(\mathrm{Al}_{2} \mathrm{O}_{3}-\mathrm{TiC}\right)$ have been proposed to minimize the negative effects of debris formation when playing aged tapes [41,47-51].

\section{Tape Degradation Problems}

It is important to consider when referring to the testing reported in this section that the testing was often done at higher-than-normal temperatures in an attempt to accelerate the degradation processes/reactions. While it is possible that accelerated testing will not identify all potential degradation processes, the lowering of the temperatures will not usually mean that the identified processes will be stopped, but only slowed. The authors realize that some of the testing was done above the recommended storage conditions for the tape, but that was only to more quickly analyze the material, not to stress test it. The reported processes below are all believed to continue at a slower pace at room temperature.

The interface temperature of the sliding surfaces (tape to head) may figure into some of the processes/reactions on a micro level. Bhushan provided a detailed analysis and calculation options. Carrying out this analysis might provide further understanding of these processes if the localized heating is high enough to locally increase the reaction rate [52].

Additives, such as dispersive products to ensure homogeneity of the magnetic particle dispersion, fillers (abrasive as "head cleaning agents"), carbon black for anti-static effect, lubricants, and stabilizers (antioxidant or anti hydrolytic agents) can be present. All these chemicals, in time, depending on their nature and environmental conditions, can modify the structure, the morphology, and chemical and 
physical properties. The first problem to face is the identification of the components of the tape. A few manufacturers marked their name and type designation on the back of the tape, but this does not guarantee the consistency of production over the long term [53]. Furthermore, in many collections, reels and boxes were separated and different tape types were also spliced together. On the bright side, sometimes information is available concerning where and under what conditions the tapes have been stored [54].

Many studies have been carried out to determine the environmental stability of tapes to evaluate lifetime expectancy $[55,56]$ It was shown that long-term stability of magnetic tape is dependent upon many factors including integrity of polymer binder and oxidation of the metal particles. It is worth noting that the chemical age of a tape cannot be understood exclusively on the basis of the calendar time, but depends on the conditions of storage. Furthermore, it is usually not possible to know the actual manufacture date of an individual tape, but the date on which the tape was recorded is easier to obtain [57].

Immediately, after widespread application of magnetic audio tapes, problems concerning dimensional, chemical, and mechanical stability emerged [58].

The most evident problems, in particular in open reel tapes, which can affect the capacity for reading, can be winding defects, cinching, curling of flange pack, slotted hubs, spoking, deformations of tapes which lie wavy, and edge damage. These damages can originate from mechanical damage or heating during manufacture, storage, or playback. The entity of the problem, which can affect the ability to keep the recording safe, is strictly dependent upon the nature of the base film. Thinner tapes are more prone to breaking, stretching, twisting, or folding, exhibiting physical and mechanical rather than chemical problems more than thicker ones. Poor tape winding can cause irreversible deformations, which may lead to severe replay problems [12].

It is worth noting that also the integrity of the tape edge has been recognized as a key to maintain high performance of reproduction of the recorded signal. SEM should be used to quantify edge quality and AFM to achieve surface height information. Cracking or damage of the mag coat can induce differences in stress distribution for the two edges during tape slitting leaving one of the edges more prone to produce debris than the other [59].

The factors influencing tape degradation are:

- Chemical nature of materials in the tape

- Manufacturing defects

- Temperature and humidity conditions over the life of the tape

- Exposure to liquids, dust, debris, or corrosive gases

- Handling history including frequent access or playback without proper conditioning or on defective equipment

- $\quad$ Exposure to strong magnetic fields

For these reasons, there is no simple method for tape degradation classification, which must be batch specific [3,6].

Storage in light and/or at high relative humidity may lead to the growth of fungus or mold on the tapes. Mold colonies may be either active or dormant (most mold will become dormant below 70\% $\mathrm{RH}[60]$ ), while active fungi will continue to damage the tape. As with other factors, there are subtleties. Florian [61] provided a more nuanced view into mold prevention and The Image Permanence Institute's Dew Point Calculator makes estimates of risk based on temperature and humidity. ${ }^{14}$ While light is often cited as a degradation factor for a variety of materials, we know of no studies addressing this with magnetic tape. Best practices recommend storing tapes within closed containers [62], which are generally opaque.

14 Dew Point Calculator: http:/ / www.dpcalc.org/ (last visited on 18 May 2019). 
Moldy tapes should be isolated from other archival materials to prevent contamination [63-65]. It is worth noting that the investigation concerning the degradation of tapes by mold and fungus are actually of relevant importance to study the biodegradation of plastics [66-68] also under gamma irradiation [69,70].

The magnetic layer is exposed to mechanical stress during playback more than other tape layers; it also contains different component other than the binder and magnetic particles, which can enable different degradation pathways.

In general, we could consider chemical degradation (due to ageing) involving: (i) the base film; (ii) the binder; and (iii) the magnetic material. The usual consequence of the degradation is decreasing of adhesion of the magnetic material to the base film and this is also accompanied by degrading mechanical properties of the tape-coating system.

\section{1. (i) Base Film Degradation}

- Acetate tapes, degrade overall by chemical decomposition with formation of acetic acid (vinegar syndrome) promoted by high temperature and humidity, but catalyzed by iron oxide. Acetic acid is able to break the bonds between the polymeric chain, thus the material becomes brittle and shrinkage is observed [3,71,72]. Consequently, the binder containing the magnetic particles separates. In addition, the components of the emulsion can separate and crystalline deposits or liquid-filled bubbles can appear. Heating is especially damaging to acetate tapes, too [3]. The thermal behavior of cellulose acetate was studied: the thermal degradation started with acetic acid formation followed by dehydration. The acid formed catalyzes the further degradation and the FTIR spectra showed that at $200^{\circ} \mathrm{C}$ the original absorptions at 1725 (>C $=\mathrm{O}$ stretching), 1375 (C-H deformation) and 1250 (-C-O- stretching) $\mathrm{cm}^{-1}$ decreased and a new band at $1580 \mathrm{~cm}^{-1}(-\mathrm{C}=\mathrm{C}-$ ) appeared, indicating the complete removal of the ester groups at $400{ }^{\circ} \mathrm{C}$ [73]. Acetate tapes should be considered unstable and at high priority for copying.

- PVC: The main way of degradation consists in the elimination of $\mathrm{HCl}$ with the formation of double bonds, which in turn can be oxidized to $-\mathrm{C}=\mathrm{O}$ or $-\mathrm{C}-\mathrm{OH}$ moieties, in the presence of oxygen and humidity. The polymer undergoes chain scission leading to a gradual deterioration of mechanical properties and chemical resistance. The entity of the $\mathrm{HCl}$ loss is depending on the presence of defects in the polymer structure (such as branching or allylic and tertiary labile chlorines).

- PET: Although the thermal stability is high, its sensitivity to humidity and the presence of trace metal ions play a significant role in the rate of degradation [74]. Thermal degradation can occur during processing into film or molded products (at $200-300^{\circ} \mathrm{C}$ ): it can start with a random breaking of the in-chain ester linkage, with formation of vinyl ester and carboxylic end groups. The transesterification of vinyl esters produces vinyl alcohol and acetaldehyde. Extraction of hydrogen can also occur promoted by metal traces giving rise to macroradicals from which hydroperoxides can be formed by reaction with oxygen with further breakdown of the polymer. In fact, even if PET is essentially a hydrophobic polymer, the ester functionality is known to undergo significant hydrolysis in moist, wet or humid conditions; under basic conditions; under UV light; or at temperature above glass transition temperature, resulting in an increase of carboxyl end groups and reduction in the molecular weight [75]. It is assumed that water diffuses into the amorphous region of the polymer where hydrolysis occurs at a rate which depends upon the shape, morphology, degree of crystallinity, relative humidity, and temperature. Experiments concerning the heat and moisture diffusion in magnetic tape packs indicated that they can be described by the heat diffusion equation for a hollow cylinder and thermal and moisture diffusivity coefficients have been shown to be anisotropic and significantly higher in the axial direction compared with the radial one [76].The evolution of molecular orientation and microstructure during and following the deformation of amorphous PET above and 
below Tg was deeply investigated by URS-FTIR spectroscopy and PM-IRLD, furnishing interesting data concerning the modifications of thin films under stress [77].

\section{2. (ii) Binder Degradation}

Temperature and humidity have been considered responsible for PE-PU binder degradation.

Hygroscopic properties of tapes have been determined by measuring their weight changes when exposed to changing levels of RH [78-81]. Many experiments have been carried out to verify the hydrolysis of the PE-PU binders. The PE-PU elastomer is a copolymer containing a large number of ester linkages, which are susceptible to attack by moisture; the dominant mode of binder breakdown is below $75^{\circ} \mathrm{C}$, in an autocatalytic process. The formation of low molecular weight carboxylic acids imparts a sticky, gummy property to the binder layer. The failures concerning the binder have been identified as sticky shed syndrome (SSS) and loss of lubricant (LoL), but can be unified in the broad term "soft binder syndrome" (SBS) [3]. By exposing tapes to different RH levels, Cuddihy $[79,80,82]$ reported that the primary chemical aging mechanism is the binder hydrolysis which was shown to be accompanied by oxidation. Accelerated ageing has been carried out exposing samples of tapes (Agfa, Scotch, and Fuji) at 100\% RH at increasing temperatures (from 50 to $90^{\circ} \mathrm{C}$ ) or exposing over saturated solutions of $\mathrm{KF}, \mathrm{NaBr}$ and $\mathrm{KCl}$, respectively. Under these conditions, the formation of hydroperoxides was detected using the standard iodometric method. It was observed that peroxides are formed, even in different amounts (minimal below $45 \% \mathrm{RH}$ ) under all the experimental condition tested and their levels decrease over ageing time in days depending on temperature and $\mathrm{RH} \%$ in a different extent for different samples $[83,84]$. In all cases, FTIR spectra of the samples showed an increasing absorption in the $\mathrm{C}-\mathrm{O}$ stretching region (around $1170 \mathrm{~cm}^{-1}$ ) due to the formation of esters, alcohols and carboxylic acid groups. It is worth noting that iron oxides are known to catalyze the decomposition of $\mathrm{RCOOH}$ moieties. FTIR analysis also indicates a marked growth in insaturation and eventual crosslinking, demonstrated by embrittlement of the material. Kinetic studies demonstrated also that the hydrolytic degradation of PE-PU elastomers is catalyzed by the carboxylic moieties formed [71,72]. Kinetics of the binder hydrolysis due to humid ageing was monitored by amount of the acetone extractable content, which was determined by weighting the tape pieces before and after acetone extraction, as a function of $\mathrm{RH} \%$, time and temperature. This study [78] aimed to individuate reasonable storage conditions (proposing $65^{\circ} \mathrm{C}$ and $40 \% \mathrm{RH}$ ).

Deterioration by-products (shorter polymers) are abraded from the tape surface and form a gooey residue on the tape-guiding parts of heads, which increase in friction, so that the replay speed is reduced, which is frequently accompanied by high-pitch squealing noises and sound distorted. Increased tape traction can cause the elongation of the PET carrier film and can lead to a complete illegibility of tapes because magnetic material adhesion is reduced or lost [85,86]. Typical binders are the ESTANE class of polymers, containing soft segments of polyester oligomers of adipic acid with 1,4-butanediol and a hard segment consisting in a very short polyurethane made from 4,4'-diphenylmethane diisocyanate molecules bonded together by urethane links to the butanediol's that serve as chain extenders (Figure 8). These polymers are known to be degraded by thermolysis, photolysis, hydrolysis, ionizing radiation, and attack by air pollutant gases. These processes can cause the molecular weight to decrease, increase, or both increase and decrease, and destroy the elastomeric properties. It was reported that the hydrolysis of the ester link is the dominant mechanism for the decrease of molecular weight under ambient temperature and humidity with chain scission and increasing of the acid concentration, according to the following general scheme $[71,87]$ : 


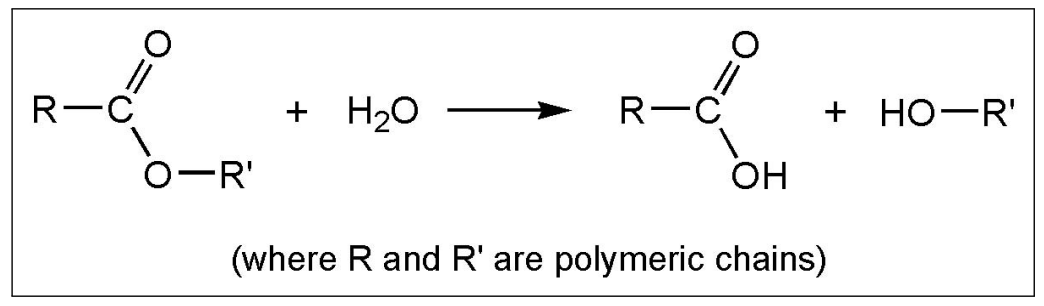

Phase-separation measurements were used in comparison with FTIR data, to evaluate the effect of hydrolysis on the soft and hard domains in the PE-PU copolymer: the IR and shear storage modulus data indicate the formation of hard segment hydrogen bonded with time leading to a reduction of conformations and increasing of crystallinity [88].

It was observed that an initial crosslinking can be induced by $\mathrm{NOx}, \mathrm{O}_{2}, \mathrm{CH}_{2} \mathrm{O}$ and ionizing radiations with subsequent degradation, too [89].

It was also demonstrated that the hydrolytic stability of polyester-polyurethanes could be significantly reduced by the presence of $\mathrm{CrO}_{2}$ (acting as on oxidant agent) much more than in the presence of maghemite [90]. The experiments have been carried out at $52{ }^{\circ} \mathrm{C}$ and $30 \% \mathrm{RH}$ on a commercially available polyester-polyurethane as a model. The polymer was significantly degraded within 60 days, as demonstrated by the low molecular weight extractable products. The oxidation of the hard urethane segment blocks by $\mathrm{CrO}_{2}$ involved oxidation of the benzylic carbons, conversion of primary aliphatic carbons to aldehydes and of secondary carbons to ketone products (see the following scheme). Related results have been obtained by analyzing through TGA mixtures of $\mathrm{CrO}_{2}$ particles slurried with the polyurethane hard-segment model: a strong exothermic signal associated with oxidation to benzophenone was observed from 35 to $80{ }^{\circ} \mathrm{C}$. The degradation products have been characterized by FT-IR, ${ }^{1} \mathrm{H}$ and ${ }^{13} \mathrm{C}$ NMR techniques.

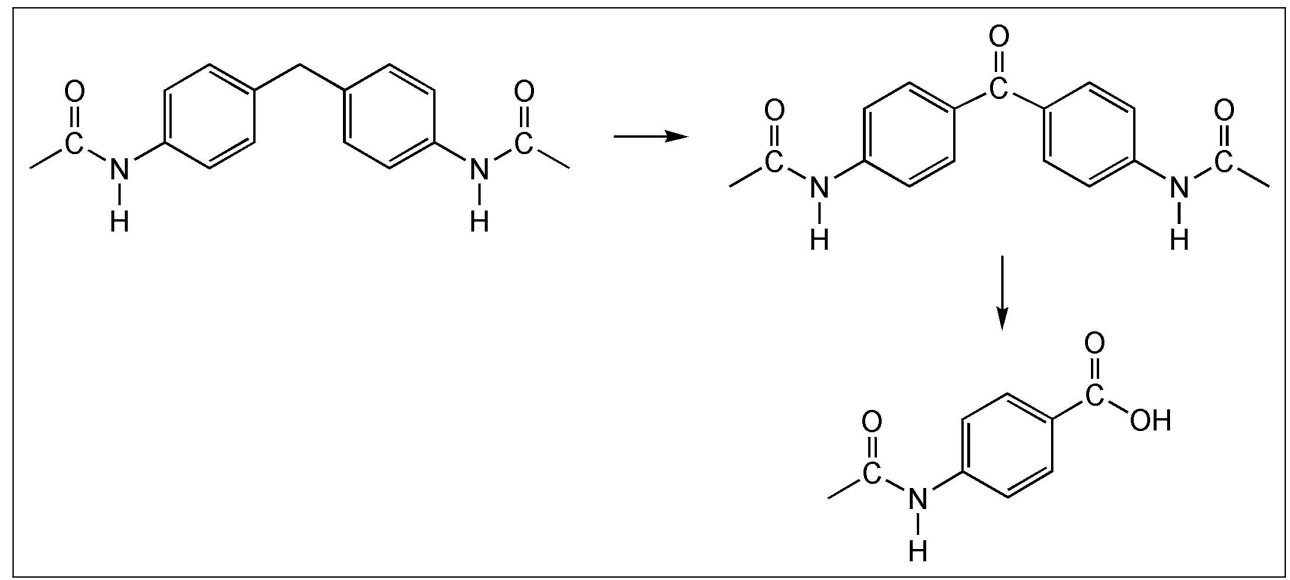

A series of experiments on system models of binders (prepared by polymer casting and adsorption of polymers on $\gamma-\mathrm{Fe}_{2} \mathrm{O}_{3}$ ) have been performed to evaluate lifetime expectancy of binder on the basis of the tensile strength change in different environmental conditions. It was observed that, by increasing the cross linking, the durability is significantly improved [85].

A relevant aspect to consider is represented by the interaction between the tape back coat and the magnetic side in the reels compressed into a high pressure contact during the storage along the time. The binders containing the magnetic material and carbon black in the back coat are quite chemically similar, if 
not identical, so that they can interact each other blocking or exchanging inorganic content, thus degrading the pristine magnetic properties.

\section{3. (iii) Stability of Magnetic Material}

Even if demagnetization of a recording due to external magnetic field is a rare phenomenon, some magnetic security screening in airports can cause partial deletion of magnetic tapes. It is suggested to keep magnetic tapes at a safe distance from transformers and electric appliances ${ }^{15}$.

Magnetic particles also degrade and distort the signal ${ }^{16}$. The coercitivity characterizes the ability to retain a magnetic field and resist to demagnetization. Magnetic materials differ in their stability: iron oxides and Co-doped iron oxides are the most stable materials of those used in audio tapes. A study concerning the long-term behavior of iron particles has been reported in a relationship with temperature and humidity on the degradation of magnetic properties [91-93].

It was observed that, as the humidity increases, the rate of the magnetic moment degradation increases. For a given temperature, it was shown that there exists a critical $\mathrm{RH}$ above which the degradation rate of magnetic moment increases markedly.

It is known that iron oxides and hydroxides (exhibiting different magnetic properties) can transform to the most stable forms goethite or hematite, depending on their origin, content of foreign ions, temperature, presence of water or humidity, morphology and crystal size. In the dry state, magnetite is readily oxidized to maghemite by air. Ultrafine crystals of magnetite change from black to the brown of maghemite even at room temperature. At temperatures $>300^{\circ} \mathrm{C}$, the transformations proceed further to hematite. In the dry state, maghemite transforms to hematite in the temperature range $370-600^{\circ} \mathrm{C}$; in hydrothermal conditions $\left(150-180^{\circ} \mathrm{C}\right)$ magnetite transforms to hematite via a dissolution/reprecipitation mechanism. It is worth noting that, in general, during these transformations, due to the different crystal structure, the density of the starting material changes (in the case magnetite $\rightarrow$ maghemite, density falls) with an increasing of weight if oxidation processes occur due to oxygen taking up. It was reported $[34,35,37]$ that, in magnetite particles larger than $300 \mathrm{~nm}$, some hematite nuclei formed even at temperature lower than $200^{\circ} \mathrm{C}$ and maghemite formation was bypassed; at $200-250^{\circ} \mathrm{C}$, crystal smaller than $300 \mathrm{~nm}$ transformed to maghemite which in turn transformed to hematite (Figure 11). It was observed that small amount of $\mathrm{OH}$ favor maghemite formation. Under UHV, a magnetite film could be converted to hematite within $30 \mathrm{~min}$ at $700{ }^{\circ} \mathrm{C}$ in the presence of oxygen. In the presence of acids, magnetite crystals transform to maghemite via an absorption reaction, which traps mobile electrons from the bulk material and reduced interfacial $\mathrm{Fe}^{\mathrm{III}}$ : $\mathrm{Fe}^{\mathrm{II}}$ ions formed can be selectively leached with further phases transformations. It is worth noting that often other metal ions, deriving from preparation, as contaminant are present, which can modify the kinetic of the transformations.

15 Online resource: "Field Strength for Partial Erasure of Magnetic Tape" derived from a report by Jay McKnight for Scully/Metrotech Div. of Dictaphone Corp. 29 October 1973. Link: http://www.mrltapes.com/field-strength-for-partialerasure.pdf (last visited on 26 April 2019).

16 Online article: Morgan, S., Product life cycle of cassette tapes: http:/ / www.avmediaplace.net/files / 46347804.pdf (last visited on 26 April 2019). 


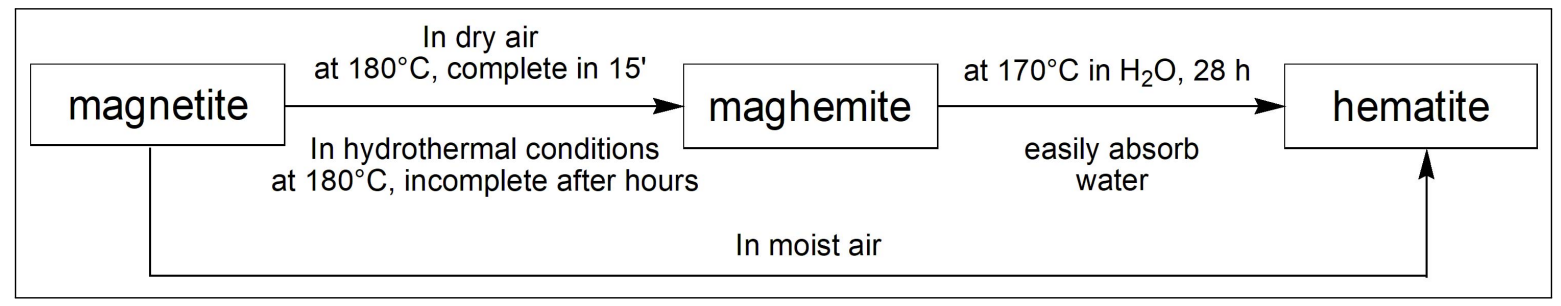

Figure 11. Kinetic of transformations of iron oxides [34,35].

Research has been carried out over the better part of the last century, in particular for data storage magnetic tapes, to improve the performance of the methods and technologies increasing capacity and consequently data rate and reliability, proposing new materials and devices, such as thin films [94]. In the case of very thin particulate data storage media, the effect of the structure on noise was investigated as a function of magnetic layer thickness [95].

The effect of temperature on the long term magnetization stability for tapes prepared from ultrafine particles of Ba-ferrite was investigated observing that, when increasing the temperature (from 295 to $338 \mathrm{~K}$ ), the oxidation of metal particles occurred significantly (with $0.04-0.07 \mathrm{~dB} /$ decade thermal decay rate) [96-98].

Metal particles (MP) and chromium dioxide $\left(\mathrm{CrO}_{2}\right)$ pigments provide a higher tape signal output and permit higher recording frequencies than the iron oxides pigments, but are less stable. A decrease of two decibels may be observed over the lifetime of the tapes bearing $\mathrm{MP} / \mathrm{CrO}_{2}$; however, the signal will still be better than a comparable iron oxide based tape. $\mathrm{CrO}_{2}$ and metal particulate are used in high grade audio tapes. Low temperature and low humidity can prevent the deterioration of pigments, which can be accelerated also by the products of the binder deterioration [63].

An intriguing study was carried out by Bowner et al. [99] concerning a comparison of the effect of accelerated aging on $\mathrm{CrO}_{2}$ or $\mathrm{Fe}_{2} \mathrm{O}_{3}$ based magnetic tapes under different environmental conditions (different temperature, relative humidity and $\mathrm{pH}$ values), by studying in particular, the magneto-TGA profiles. It was observed that magnetic changes in tapes occurred and arose from either a chemical change in the metal oxide to a non-magnetic state or a permanent loss in the ordering of the magnetic particles. At $85^{\circ} \mathrm{C}$ and $85 \% \mathrm{RH}$, degradation of the adhesive bond between the magnetic particles and the PET substrate also caused disruption of the particle array. The study demonstrated that $\mathrm{CrO}_{2}$-tapes were less stable than the $\mathrm{Fe}_{2} \mathrm{O}_{3}$-based tapes in all ageing experiments performed, indicating a synergism between the acid-catalyzed hydrolysis of the binder that holds the magnetic particles to the PET substrate and the thermally-induced physical degradation that disordered the particle array on the tape creating defect sites.

A patent proposed to improve $\mathrm{CrO}_{2}$ particles stability protecting against reactions with organic binders and water, by generating on the surface a more stable phase by treating with a reducing agent [100].

A plasma polymerized protective layer (in hexamethyldisiloxane or acrylonitrile) against corrosion was proposed to protect $\mathrm{Co:Ni}$ 80:20 alloy thin films suitable for magnetic data storage [101].

\section{Analytical Methods to Characterize the Tapes Components and to Study the Degraded Tapes}

As discussed above, a key point is the identification of the type of base film and nature of the chemicals in the tape. Problems can be associated with a group of tape types sharing coming characteristics, a single tape type, or just certain batches of one or more tape types. As mentioned elsewhere, it is often very difficult to determine the specific manufacturer and type of tape, but when it is known it eases the diagnosis of typical failure modes (an example is the base-binder adhesion failure in some batches of 
Scotch 201).

(a) Microscopy techniques. To undertake a preliminary characterization, ESEM or SEM together with XRF determinations could give rapid and extremely important information furnishing immediately data concerning the magnetic side of the tape, the nature of the magnetic material (iron and/or chromium oxides), the nature of base film in terms of presence of chlorine or not, indicating the presence of PVC or not, and the presence of other heteroatoms in the binder or lubricant (such as silicon or fluorine). Furthermore, the thickness is possible to measure and the presence of morphological damages can be observed [54]. Some authors reported a series of ESEM images together with XRF analytical date of 10 tapes (some of which unknown) to achieve preliminary data concerning the morphology, the elemental chemical composition and the presence of damages: in particular, the images of the cross-sections (simply achieved by gently braking of the tapes) showed that the samples were significantly different each other as for the relative thickness of the top coat and the substrate. Furthermore, in some cases, the base film appeared to be separated from the magnetic layer, suggesting that these tapes could present problems during playing with possible loss of magnetic material (Figures 12 and 13). The morphological observations have been accompanied by XRF analyses.

In Figure 13, ESEM images of the magnetic side of an aged BASF audio tape (model unknown) have been reported. The images have been recorded in back scattering mode, which indicates through different grey tones a different composition. In the photo, "lighter" spots compared with the average material are present: the XRF analysis shows that the atomic ratio Fe/O in the "grey" part is about $3 / 4=0.75$ and in the "light" parts is about $2 / 3=0.67$. Thus, the data suggest that a conversions from magnetic magnetite $\mathrm{Fe}_{3} \mathrm{O}_{4}$ to weakly magnetic hematite $\mathrm{Fe}_{2} \mathrm{O}_{3}$ occurred: the latter having higher density justifies the appearance of voids in the magnetic layer close to the light spots.

TEM micrographs have been used to evaluate the thickness of tape layers of IBM 3590 samples conditioned in accelerated temperature/humidity environments for different times as an indication of degradation amount in comparison with recording/playback performance. It was observed that the major mechanism for degradation and lifetime limits for tapes is oxidation of the metal particles from ferromagnetic iron to a non-ferromagnetic iron oxide [55].

(b) Spectroscopic techniques. The FT-IR spectroscopic technique has been extensively used either to characterize tapes or to evaluate the degradation amount, on the basis of the wide literature concerning the application of spectroscopic techniques to study polymers' chemistry and modifications for instance under heating [102] or stress [77]. Gómez-Sánchez [103] reported the data collected by recording the ATR spectra of a large number of tapes belonging to the archive at the Ethnological Museum of Berlin for which very little information on the damages or actual conservation state was available. A series of bands characteristic of base polymeric films and of the binders have been identified, including modifications due to degradation. Hobaica [104] identified spectral differences between SSS and non-SSS audio magnetic tapes: the shape of the carbonyl peak (in the range 1730 to $1693 \mathrm{~cm}^{-1}$ ), the presence of a peak at $1364 \mathrm{~cm}^{-1}$ in SSS tapes (due to $\mathrm{CH}_{2}$ wagging indicating differences in molecular weight and orientation in polyester soft segment), the presence of a shoulder at $1252 \mathrm{~cm}^{-1}$ and of a peak at $1138 \mathrm{~cm}^{-1}$ (attributed to the formation of additional C-O bonds due to hydrolysis). In particular, SSS tapes spectra had a more pronounced free carbonyl peak at $1725 \mathrm{~cm}^{-1}$ with respect to the signal attributed to the hydrogen bonded carbonyls at $1701 \mathrm{~cm}^{-} 1$ : for SSS tapes the main carbonyl peak absorption ratio $\mathrm{A}_{1725} / \mathrm{A}_{1701}$ was observed of 1.03 and of 0.88 for non-SSS tapes. In addition, the amide bands of the hard segment of PE-PU were studied comparing the absorption ratios for the amide peaks at 1527, 1308, and $1219 \mathrm{~cm}^{-1}$ for SSS and non-SSS tapes. It was observed that they did not change significantly, thus indicating that chemical changes were not occurring in the polyurethane's amide moieties, but are associated with the soft PE segment. The spectra after baking 
of tapes were also compared: again, significant spectral changes have been observed only for the soft PE segment with a decreasing of the signal of free carbonyl bonds (Table 2). Recently, an accurate investigation was carried out in order to demonstrate that, by applying a multivariate principal statistical analysis to a large number of ATR-FTIR data (in the spectral range $1750-950 \mathrm{~cm}^{-1}$ ), it is possible to distinguish playable from non-playable tapes with a non-destructive technique [105].

Table 2. FT-IR characteristic absorptions of PE-PU binder. Data from [104].

\begin{tabular}{|c|c|c|c|}
\hline $\begin{array}{l}\text { Literature Assigned } \\
\text { Segment Model }\end{array}$ & $\begin{array}{l}\text { Literature Molecular Assignment } \\
\text { (Peak Intensity) }\end{array}$ & $\begin{array}{l}\text { Peak } \\
\text { Wavenumber }\left(\mathrm{cm}^{-1}\right)\end{array}$ & Effect of Hydrolysis \\
\hline Both & $v(\mathrm{C}=\mathrm{O})$ free, $(\mathrm{VS})$ & $1728-1721$ & More intense in SSS tapes \\
\hline Polyurethane & $v(\mathrm{C}=\mathrm{O})$ hydrogen bonded, $(\mathrm{VS})$ & $1701-1689$ & Less intense in SSS tapes \\
\hline Polyurethane & $\delta(\mathrm{C}=\mathrm{C})$ aromatic ring, $(\mathrm{S})$ & $1596-1591$ & - \\
\hline Polyurethane & $\delta(\mathrm{N}-\mathrm{H})+v(\mathrm{C}-\mathrm{N})$ & $1529-1522$ & $\begin{array}{l}\text { Amide peak: no change between } \\
\text { SSS and non-SSS tapes }\end{array}$ \\
\hline Polyester & $\delta\left(\mathrm{CH}_{2}\right),(\mathrm{W})$ & $1462-1453$ & - \\
\hline Polyurethane & $v(\mathrm{C}-\mathrm{C})$ phenyl ring, $(\mathrm{S})$ & $1413-1409$ & - \\
\hline Polyester & $\mathrm{w}(\mathrm{CH} 2),(\mathrm{W})$ & $1373-1356$ & More intense in SSS tapes \\
\hline Polyurethane & $\delta(\mathrm{N}-\mathrm{H})+v(\mathrm{C}-\mathrm{N})$ & $1311-1305$ & $\begin{array}{l}\text { Amide peak: no change between } \\
\text { SSS and non-SSS tapes }\end{array}$ \\
\hline Polyester & $v(\mathrm{C}-\mathrm{O}-\mathrm{C}), \mathrm{w}\left(\mathrm{CH}_{2}\right),(\mathrm{W}-\mathrm{M})$ & $1257-1249$ & $\begin{array}{l}\text { Present in most SSS tapes (new } \\
\text { C-O bonds) }\end{array}$ \\
\hline Polyurethane & $\delta(\mathrm{N}-\mathrm{H})+v(\mathrm{C}-\mathrm{N})$ & $1220-1213$ & $\begin{array}{l}\text { Amide peak: no change } \\
\text { between SSS and non-SSS } \\
\text { tapes }\end{array}$ \\
\hline Polyester & $v(\mathrm{C}-\mathrm{O}-\mathrm{C}),(\mathrm{S})$ & $1173-1156$ & - \\
\hline Both & $v(\mathrm{C}=\mathrm{O})+v\left(\mathrm{O}-\mathrm{CH}_{2}\right),(\mathrm{M})$ & $1141-1134$ & $\begin{array}{l}\text { Present in most SSS tapes (new } \\
\mathrm{O}-\mathrm{CH}_{2} \text { moieties) }\end{array}$ \\
\hline Both & $v(\mathrm{C}-\mathrm{O}-\mathrm{C}),(\mathrm{S})$ & $1073-1060$ & More intense in SSS tapes \\
\hline Both & $v($ Aryl-O), (M-S) & $1020-1015$ & More intense in SSS tapes \\
\hline
\end{tabular}




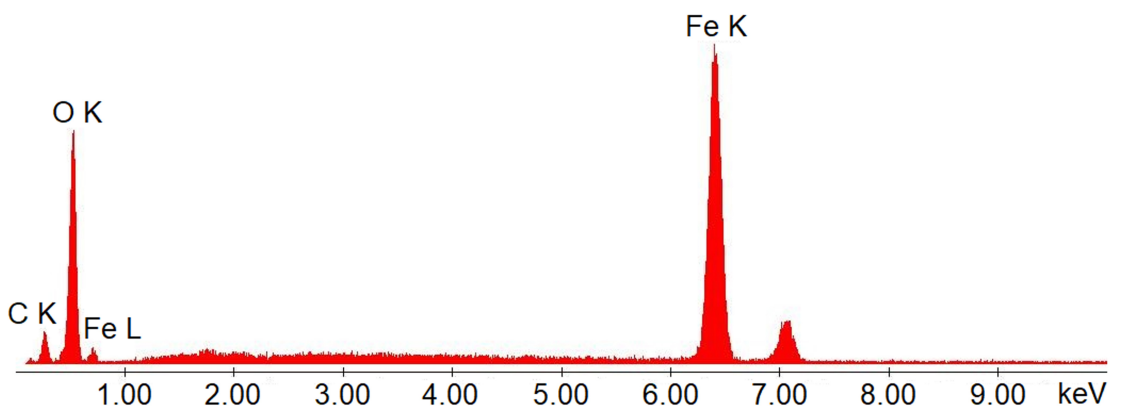

$\mathrm{XRF}$ analysis of the magnetic side of tape $\mathbf{1}$ : only iron oxides are present.

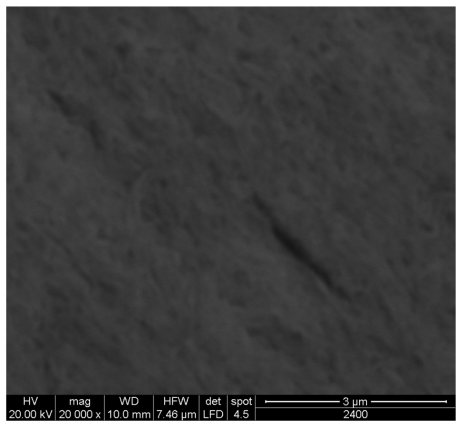

ESEM image of the magnetic side of tape 1: disomogeneities along the axial direction in the magnetic layer are visible (20 000X).

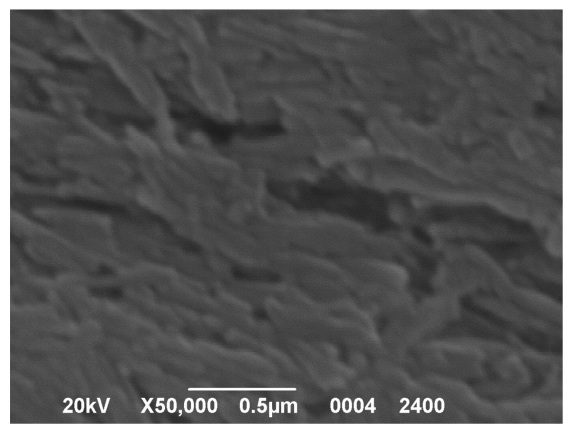

SEM image of the magnetic side of tape $\mathbf{1}$ : defects (voids) in the magnetic layer are visible (50 000X).

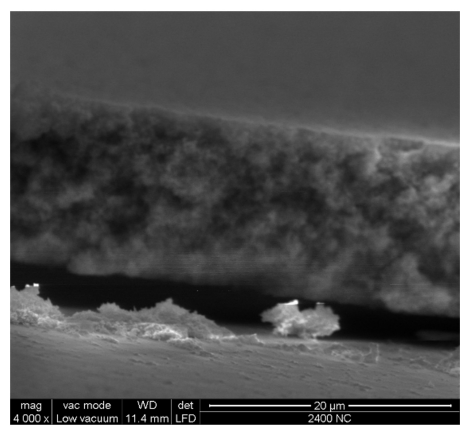

ESEM image (4000X) of a cross section of tape 1 . It is evident the bad adhesion of the magnetic layer (up) to the polymeric base film.

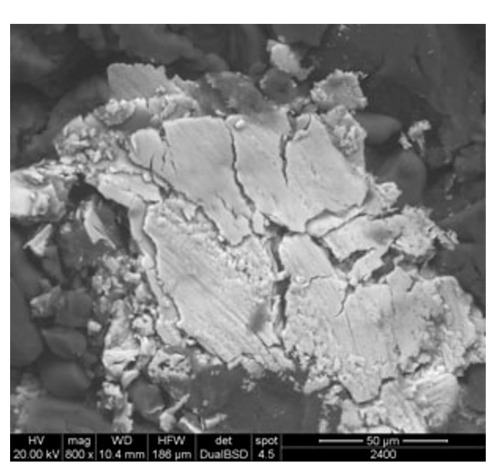

An ESEM image of a zone of the residue left by tape $\mathbf{1}$ on the heads during playing: the lighter (white) part indicates the presence of heavier elements (metals) than the grey part (polymers containing carbon)

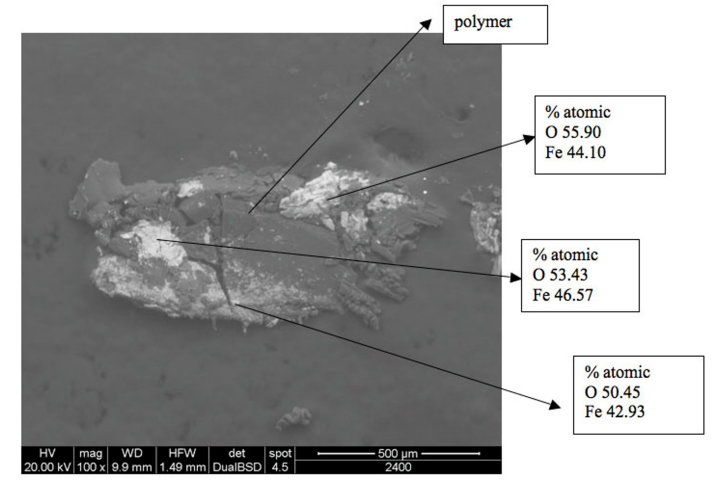

An ESEM image of the residue left by tape $\mathbf{1}$ during playing, together with the analysis carried out inside the instrument through XRF. In all examined zone the $\mathrm{Fe} / \mathrm{O}$ atomic ratio is about 0.8 , slightly higher than 0.75 of magnetite $\left(\mathrm{Fe}_{3} \mathrm{O}_{4}\right)$. The loss of material containing iron oxide indicates loss of information.

Figure 12. Electron microscopy images and data collected on an unknown magnetic audio tape $\mathbf{1}$ and on the residue left by the tape on the heads during playing. (Data collected by the authors and not previously published.) 


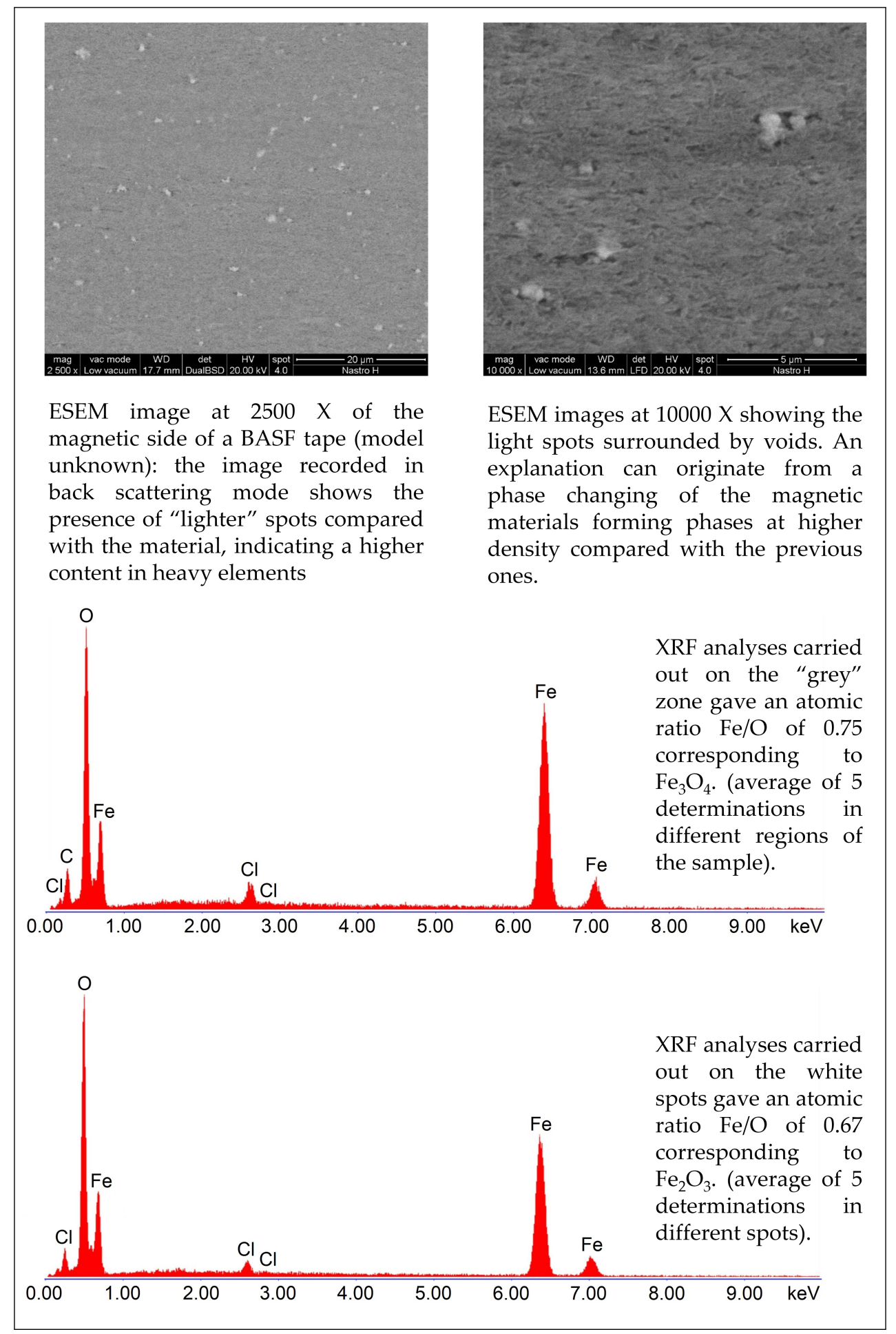

Figure 13. ESEM images of the magnetic side of an aged BASF audio tape (model unknown). (Data collected by the authors and not previously published.)

In Figure 14, examples of the ATR FT-IR spectra of the shiny and the matte sides of the unknown magnetic audio tape 2 are reported. 
Both FT-IR and Raman techniques are used also to distinguish magnetite from maghemite, resulting these methods more useful than X-ray powder spectra which are almost identical for these two phases [106]. Common IR and Raman absorptions are reported in Table 3.

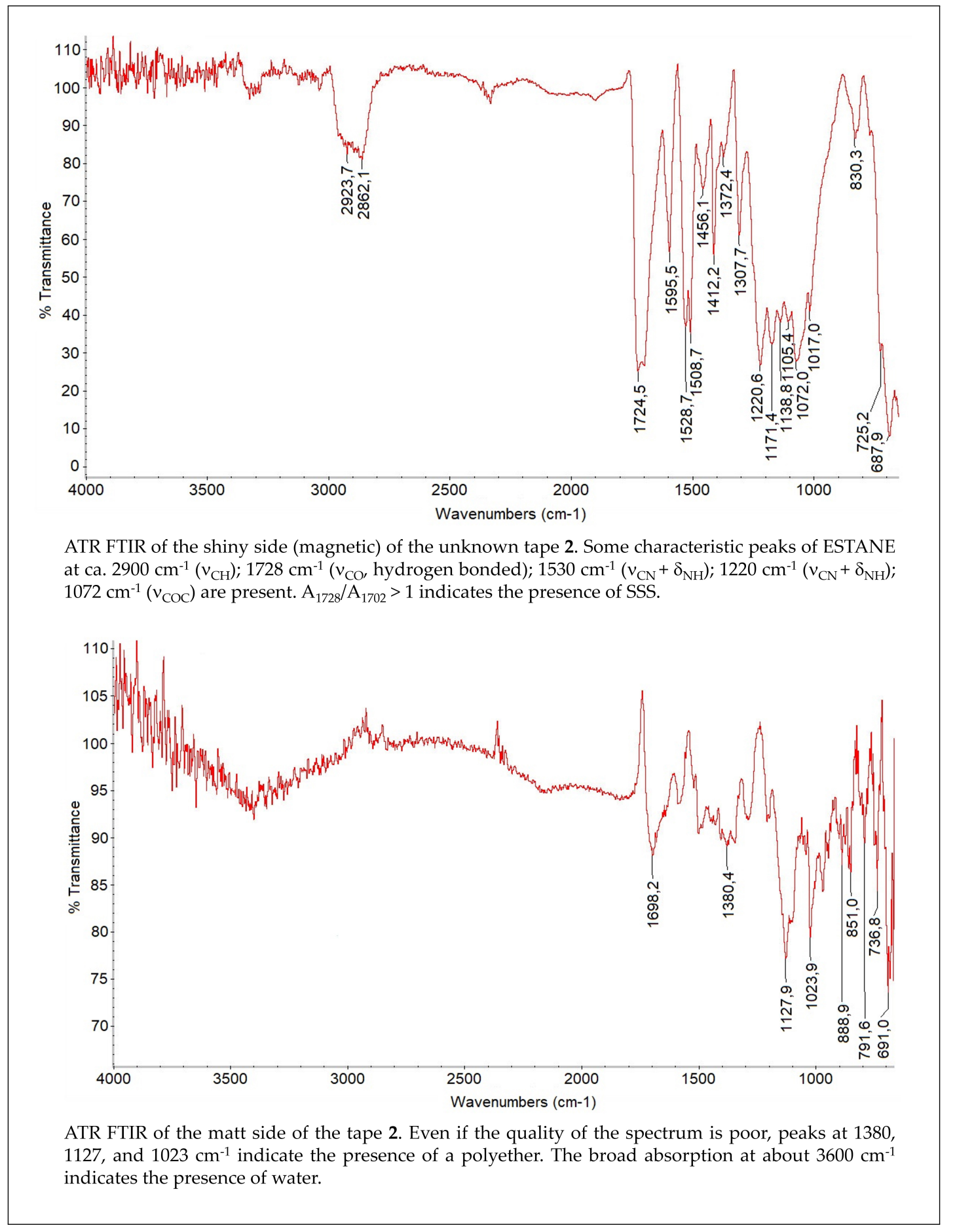

Figure 14. The ATR FT-IR spectra of the shiny and the matte side of an unknown magnetic audio tape 2 . (Data collected by the authors and not previously published.) 
X-ray diffraction spectra originate from diffraction of radiation occurring because the incident wave has a wavelength of the same order of magnitude as the spatial periodicity with which scattering centers in the sample are arranged. The diffraction condition is given by Bragg's law: $\mathbf{2 d} \sin \theta=\mathbf{n} \lambda$ (where $\mathrm{n}$ is an integer, $\lambda$ is the wavelength of the radiation, $\Theta$ is the angle between the incident beam and the diffracting planes and $\mathrm{d}$ is the spacing between those planes).

Table 3. FT-IR and Raman characteristic absorptions of some iron oxides (data from [37,106]).

\begin{tabular}{llllll}
\hline Mineral Name & $\begin{array}{l}\text { Goethite } \\
\alpha \text {-FeOOH }\end{array}$ & $\begin{array}{l}\text { Lepidocrocite } \\
\gamma \text {-FeOOH }\end{array}$ & $\begin{array}{l}\text { Hematite } \\
\alpha-\mathrm{Fe}_{2} \mathbf{O}_{3}\end{array}$ & $\begin{array}{l}\text { Magnetite } \\
\mathbf{F e}_{3} \mathbf{O}_{4}\end{array}$ & $\begin{array}{l}\text { Maghemite } \\
\gamma-\mathrm{Fe}_{2} \mathbf{O}_{3}\end{array}$ \\
\hline Infrared bands $\left(\mathrm{cm}^{-1}\right)$ & $\begin{array}{l}1667,1399,1260, \\
881,793,608\end{array}$ & $\begin{array}{l}1625,1152,1017, \\
737\end{array}$ & $535,464,308$ & 570,390 & $\begin{array}{l}730,696,636, \\
590,570\end{array}$ \\
\hline \multirow{2}{*}{ Raman lines $\left(\mathrm{cm}^{-1}\right)$} & $\begin{array}{l}243,299,385, \\
479,550,685,993\end{array}$ & $\begin{array}{l}220,250,309,377,527,648 \\
350,225,498,247\end{array}$ & $300,532,661$ & $350,500,700$ \\
\hline
\end{tabular}

Powder diffraction is used in samples in which it is assumed that every possible orientation of the crystal lattice is present and a suitable single crystal of the sample is not available. The spectrum shows lines which correspond to the $2 \theta$ values satisfying Bragg's law according to different planes distances, being characteristic of the crystalline structure. Maghemite and magnetite exhibit quite similar X-ray powder spectra. Furthermore, the spectra depend on how the sample was synthesized, so that good information to distinguish iron oxide can be achieved overall by using standards. In Table 4, some data regarding the crystalline structure of some iron oxides are reported.

In Figure 15, an example of the XRD spectrum carried out on the magnetic side of the unknown audio tape 3 is reported. The intense signals of maghemite $\gamma-\mathrm{Fe}_{2} \mathrm{O}_{3}$ and the small ones of hematite $\alpha-\mathrm{Fe}_{2} \mathrm{O}_{3}$ are well visible (Table 4).

Table 4. General data regarding crystalline structure and properties of some iron oxides. $\star$ Curie temperature. Data from [34].

\begin{tabular}{|c|c|c|c|c|c|}
\hline Mineral Name & Goethite $\alpha$-FeOOH & Lepidocrocite $\gamma$-FeOOH & Hematite $\alpha-\mathrm{Fe}_{2} \mathrm{O}_{3}$ & Magnetite $\mathrm{Fe}_{3} \mathrm{O}_{4}$ & Maghemite $\gamma-\mathrm{Fe}_{2} \mathrm{O}_{3}$ \\
\hline & $\begin{array}{l}a=0.9956 \\
b=0.30215 \\
c=0.4608\end{array}$ & $\begin{array}{l}\mathrm{a}=0.307 \\
\mathrm{~b}=1.253 \\
\mathrm{c}=0.388\end{array}$ & $\begin{array}{l}\mathrm{a}=0.50356(1) \\
\mathrm{c}=1.37489(7)\end{array}$ & $\mathrm{a}=0.8396$ & $\mathrm{a}=0.834741$ \\
\hline Cell dimension $(\mathrm{nm})$ & orthorhombic & orthorhombic & $\begin{array}{l}\text { rhombohedral } \\
\text { hexagonal }\end{array}$ & cubic & cubic or tetragonal \\
\hline Formula units, per cell & 4 & 4 & 6 & 8 & 8 \\
\hline Density $\left(\mathrm{gcm}^{-3}\right)$ & 4.26 & 4.09 & 5.26 & 5.18 & 4.87 \\
\hline Color & yellow-brown & orange & red & black & reddish-brown \\
\hline Type of magnetism & antiferromag. & antiferromag. & $\begin{array}{l}\text { weakly ferromag. or } \\
\text { antiferromag. }\end{array}$ & ferrimag. & ferrimag. \\
\hline Neel temperature $\left({ }^{\circ} \mathrm{C}\right)$ & 400 & 77 & $(956) \star$ & $(850) \star$ & $(820-986) \star$ \\
\hline
\end{tabular}

(c) GC-MS techniques. The emission of VOCs in magnetic tapes after decades of natural ageing or after artificial ageing has been studied by using headspace SPME-GC-MS technique (sample collected from $30 \mathrm{~cm}$ of magnetic tape cut, put in a headspace glass vial and heated at $60^{\circ} \mathrm{C}$ for 5 min or directly mounting the fiber holder inside the player next to the surface of the running tape) with the aim to identify chemical degradation markers [107]. A wide variety of VOCs was detected including both oxygen-containing compounds (carboxylic acids, esters, ketones, lactones, aldehydes), and hydrocarbons such as linear alkanes. Some of the compounds extracted at $60^{\circ} \mathrm{C}$ were identified as additives dependent on the proprietary formulation of the manufactures. Typical fatty acid ester lubricants with an even number of carbons (from 12 to 22) and alcohols with 3 to 13 carbons, were detected together with butylated 
hydroxytoluene, a widely used phenolic antioxidant, p-benzoquinone (reasonably added for inhibition or retardation of free-radical polymerization during manufacturing process) and phtalates as plasticising agents. In addition, homogeneous series of carboxylic acids (such as acetic acid and hexanoic acid), ketones (in particular from 2-octanone to 2-dodecanone, acetophenone and cyclohexanone), furanones (such as 5-hexyldihydro-2(3)-furanone) and aldehydes (from hexanal to undecanal and benzaldehyde) have been detected for all tapes under investigation after ageing.

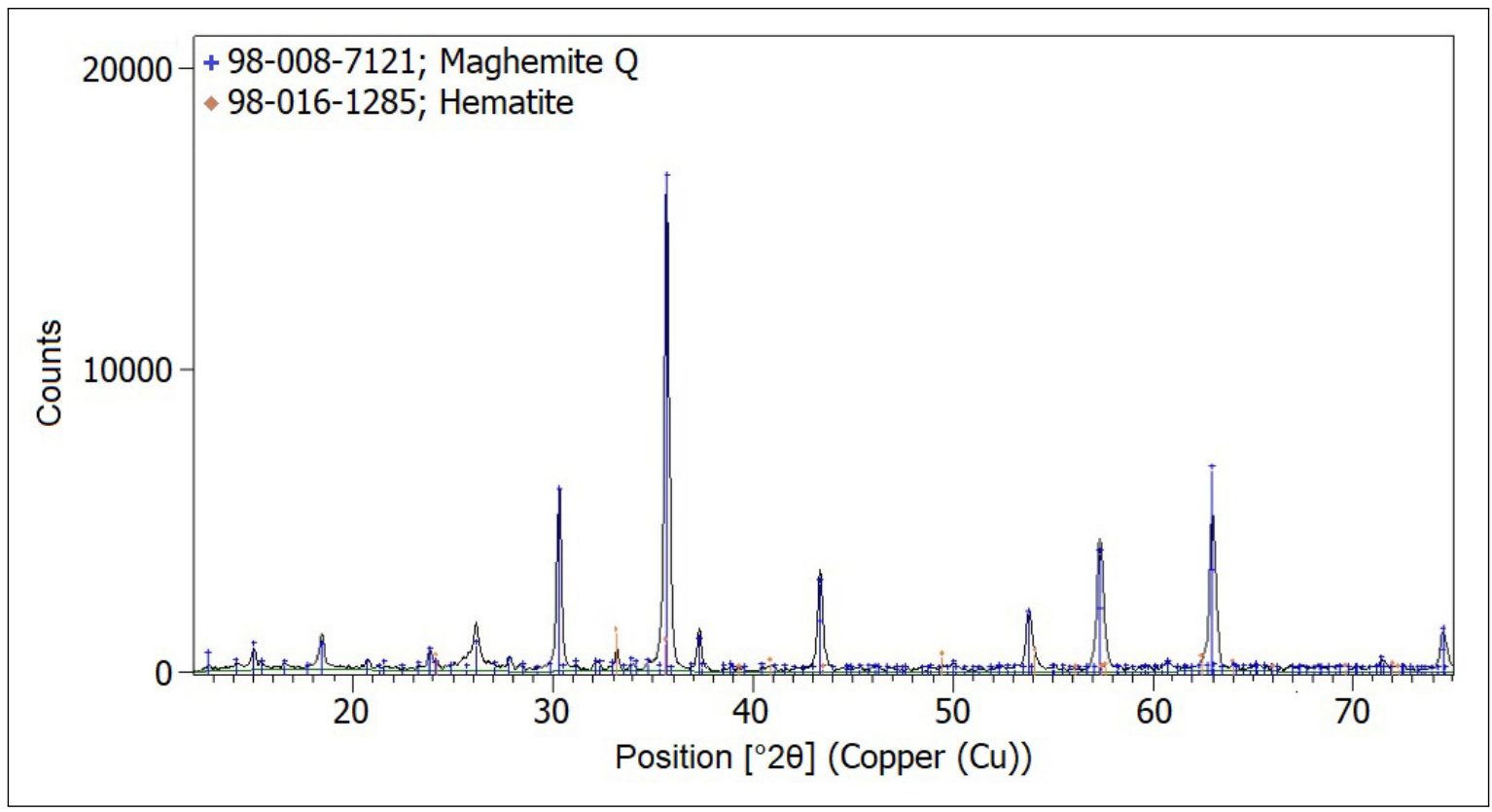

Figure 15. XRD spectrum carried out on the magnetic side of the unknown audio tape 3 . The spectrum has been collected by using a Cu source. (Data collected by the authors and not previously published).

It is worth noting that, to evaluate the hydrolytic tape stability and to use the results as ageing test, pyrolysis $\left(\right.$ at $280^{\circ} \mathrm{C}$ ) coupled with GC-MS analyses have been carried out on naturally aged U-matic videotapes [108] with PET as base film and PE-PU as binder. It was confirmed that low molecular weight compounds were present by analyzing through size exclusion chromatography of the THF extracts.

(d) Extraction tests. The most used methods to quantify the degree of degradation of the tapes are destructive and consist in extraction with solvent (in particular, acetone) of the soluble compounds formed by degradation [109] and the weight percentage of extractable was considered to be a measure of the degradation. In Figure 16, the effect of the treatment with acetone on an aged Scotch/3M (model unknown) is shown. The tape was recognized, by FT-IR data, bearing PET as polymers base film and resulted to be completely destroyed when treated with acetone [110]. The extracts, taken to dryness, can be characterized by GC-MS and spectrophotometric determination (such as FTIR, ${ }^{1} \mathrm{H}$ and ${ }^{13} \mathrm{C}$ NMR) [111]. 


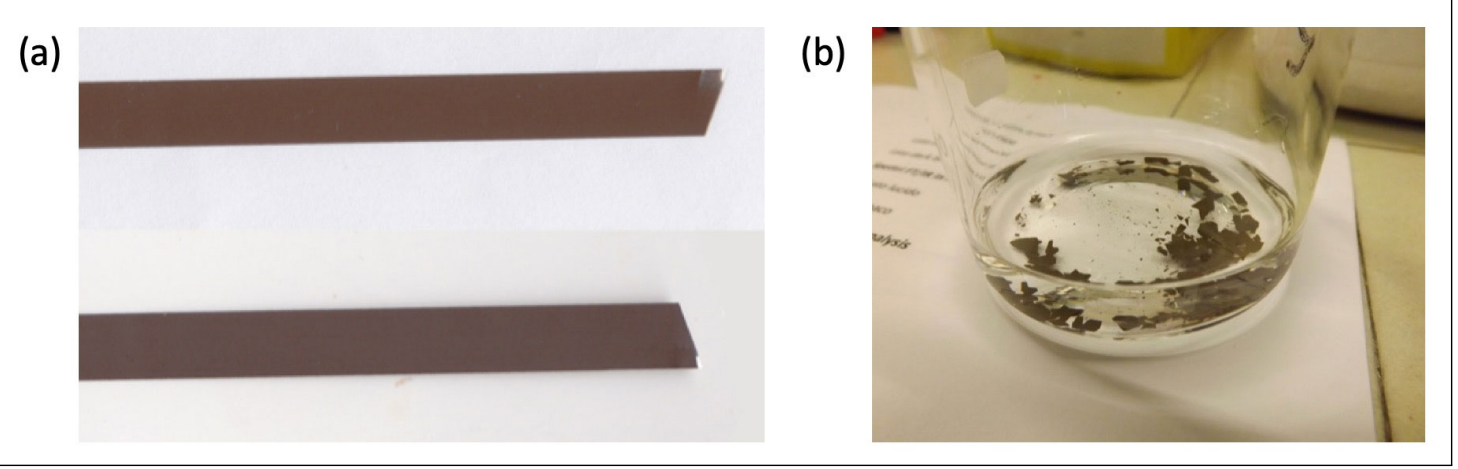

Figure 16. Photos of an aged Scotch/3M (model unknown) audio tape before and after treatment in acetone. (a) Images of the shiny side (light brown) and of the matte side (slightly darker brown). The ESEM determination indicates that the matt side carries the magnetic material. It shows (by the XRF determination) the presence of $\mathrm{Fe}$ and $\mathrm{O}$ in about 1:1 atomic ratio. (b) Image of the tape after treatment with acetone: the tape appears completely destroyed. The tape breaks giving small fragments. (Photos collected by the authors and not previously published.)

(e) Acidity Test. The formation of acids has been reported to occur due to degradation; thus, the test can be used as an indicator of tape conditions. The test consists in the extraction of acids in water $\left(48 \mathrm{~h}\right.$ at $\left.38^{\circ} \mathrm{C}\right)$ and their titration with $\mathrm{NaOH}$ (meta-cresol purple indicator) [109].

(f) Thermal behavior determinations. For the characterization of unknown tapes, the thermal behavior through TGA determination has been proposed [112]. Examples are reported in Figure 17. The observation that the degradation temperatures are quite different indicates that the two tapes contain different component: in particular, the most relevant degradation process at temperature higher than $400{ }^{\circ} \mathrm{C}$ is in agreement with the hypothesis that the tape in Figure 17a has PET as the base film, while the tape in Figure 17b has cellulose acetate as the base film exhibiting degradation processes at lower temperatures ${ }^{17}$.

Recently, Davis [113] reported some results concerning the thermal changes (through DSC determinations) occurring in tape materials under ordinary storage, operating and baking temperatures. He observed that degraded tapes show a broad, irreversible, endothermic transition at about $50^{\circ} \mathrm{C}$, generally absent in playable tapes. Furthermore, he observed by SEM that solid aggregates or defects contaminated the oxide layer surface of unplayable tapes, which disappeared upon heating, providing a smooth homogeneous oxide surface similar to the non-degraded tapes, which were most likely soft-segmented polymeric degradation products.

(g) Other determinations. As the binder deteriorates, it becomes sticky and may cause increasing friction, along the tape during playback. Thus, a nondestructive friction test has been proposed and standardized by ISO for motion-picture films [114].

It was reported that for two ESTANE polyester polyurethanes (ESTANE 5701, a linear one, and ESTANE 5706, a sterically hindered polymer) the presence of $\mathrm{CrO}_{2}$ pigment resulted in modulus reinforcement in the same manner as a conventional filler: higher pigment loading showed higher storage modulus in the glassy region. The addition of dispersant (which stay mostly on the surface of the pigment)

17 Cinko, G.R., "TGA study of thermal degradation of plastic films": http:/ / bit.ly / giselaTapes (last visited on 26 April 2019). 
and lubricants (which disperse in the polyurethane matrix as a plasticizer) showed some effects on mechanical properties [115].

In addition, physical-mechanical determinations have been carried out to characterize magnetic tapes made from PET and PEN: creep compliance, shrinkage, and dynamic mechanical analysis have been shown to be dependent upon temperature, which induces molecular movement providing dimensional instability, influenced also by processing methods [116].

Magneto-resistive microscopy has been shown to be useful for forensic analysis of audio tapes to recover data from specific areas of the tapes not accessible to standard players and for reading very old tapes that cannot be played ${ }^{18}$ [117].

To study the morphology, structure and degradation of tapes bearing very thin metal evaporated coatings as magnetic component, X-ray photoelectron spectroscopy (XPS) and Secondary Ion Mass Spectrometry (SIMS) determinations have also been carried out. A key point of the study was the optimization of the experimental details to achieve measurements able to furnish informative data on this particular kind of sample, which can degrade under the measurement conditions. The data demonstrated that in all the sample under study perfluoropolyethers have been used as lubricants, being this material able to realize and maintain a continuous coverage to protect the metal film, avoiding spacing losses even under severe wear. Superior measurement durability was observed for the tape exhibiting significantly greater thickness and higher semi-mobile component in the lubricant able to repair localized film damage due to tribological contact [118].

18 See slides "Magnetic Forensics" presented by David Pappas of the National Institute of Standards \& Technology at the THIC Meeting at the National Center for Atmospheric Research in 2006: http:/ / www.thic.org/pdf/July06/nist.dpappas.060718.pdf (last visited on 25 April 2019). 


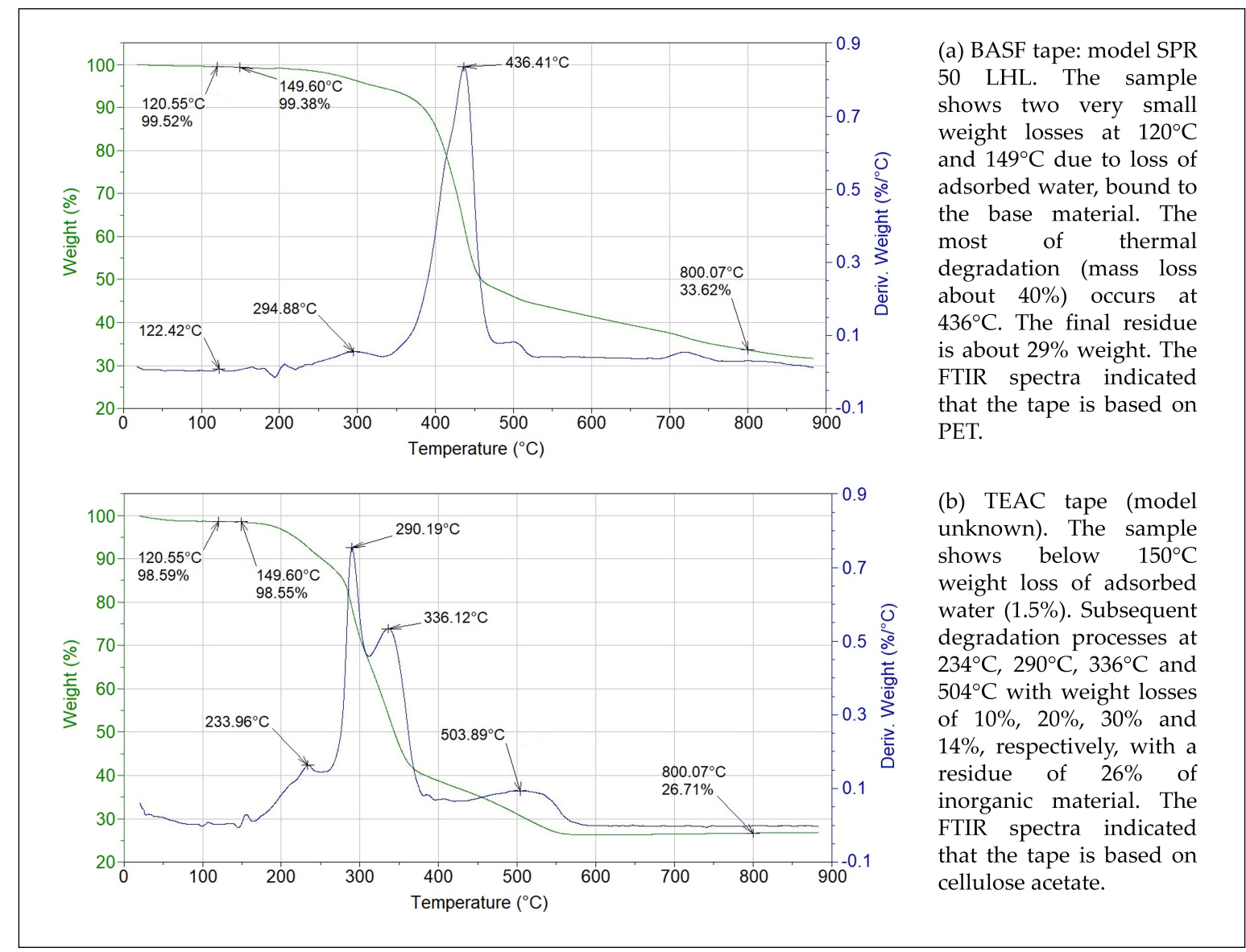

Figure 17. TGA determinations of two aged magnetic audio tapes carried out under nitrogen, heating rate $10^{\circ} \mathrm{C} / \mathrm{min}$. (Data collected by the authors and not previously published.)

A rapid test to assess tape condition was proposed by Davis [113] using contact angle measurements. He observed that, in general, degraded tapes showed contact angles less than $90^{\circ} \mathrm{C}$ on both sides of the tape, while tapes in good conditions show contact angles higher than $100^{\circ} \mathrm{C}$, in agreement with higher hydrophobicity properties.

\section{Restoration}

There are a few different restoration techniques that are in daily use around the world. Other techniques to render otherwise unplayable tapes playable are used as the need arises. The goals of these techniques is to render the tape playable at full quality in order to copy/digitize the content.

\section{Thermal treatment ("baking")}

Perhaps the most widely used restoration method is the baking of tapes with "sticky shed syndrome" [119]. These are typically back-coated tapes on PET base film. Acetate based tapes should never be baked. Baking rarely renders a tape permanently playable [112]. Ongoing conversations indicate that baking times appear to be increasing, but one correspondent reports that 30 days backing for 16-inch reels of 1-inch instrumentation tape on windowless precision reels works very well [120]. 


\section{Cold playback}

One of the authors reported success with cold playback in 2012 [121]. In studying potential failure modes of recording tape, he became aware of the glass transition temperature (Tg) of the coating and the fact that degradation may lower the Tg of the coating, producing stick-slip as the tape moved past stationary items (such as heads and guides) in the tape path. Some tapes which showed evidence of stick-slip (audible squealing from the tape and in the audio) were analyzed. One sample showed a $\mathrm{Tg}$ of about $8^{\circ} \mathrm{C}$ and another showed that the normal lubricant load for the tape was still present. Although these tapes that showed stick-slip (without shedding) were often referred to as suffering from "loss of lubricant" that apparently was not the case, as chemical analysis showed there was still a full lubricant load in the tape. While over-lubricating the tape can render these tapes playable, the additional lubrication can interfere with the mechanics of the tape transport. We have received reports of cold playback at around $4{ }^{\circ} \mathrm{C}$ to be successful in reducing or eliminating the stick-slip. We suspect that as these degradation modes continue to advance, that even lower temperatures might be necessary.

\section{Adding more lubricant}

It is possible to add more lubricant to the tape-head interface, which reduces or eliminates stick-slip. Marie O'Connell from New Zealand settled on isopropyl alcohol as that was certainly a technique that received some traction in the $1980 \mathrm{~s}$ and $1990 \mathrm{~s}^{19}$.

The interesting thing about this technique is, while the alcohol provides a lubricating film, it also provides a cooling effect. In recent conversations, $\mathrm{O}^{\prime}$ Connell reported to Hess that more tapes were being baked and the alcohol drip was being reserved for tapes that did not respond to baking.

Scott Dorsey, who works at NASA as an instrumentation support technician, suggested using D5 or decamethylcyclopentasiloxane as a lubricant ${ }^{20}$. It evaporates relatively quickly so even if a tape mechanism is contaminated, it will return to normal working order in a few days. Recent research still considers this a safe product, which is reassuring as it is widely used in personal care products to provide the slippery feel [122]. One of the authors (Hess) has had good results for certain types of tapes with this lubricant.

One of the challenges is knowing when to lubricate, when to use cold playback, and when to bake. It is made more important to learn how to do this type of triage because using the wrong treatment may not be neutral to the degrading tape. We have found no gross ill effects on baking tapes that will respond to cold playback or adding lubrication, but subtle effects have been reported that the baking may exacerbate the degradation that has already occurred without ameliorating it.

\section{Preservation, Handling, Storage}

Guidelines for storage of reel of tape have been proposed, but many of the points have not gained wide acceptance and are controversial. In today's operational environment, digitization of tapes with file storage in trusted digital repositories is the primary method of preserving the content of old tapes ${ }^{21}[11,63,121,123]$

- $\quad$ Tapes must be wound end-to-end, onto a rigid hub, before being put into storage to avoid pack tension distortions.

- Any residue from degradation should be removed as long as there is no further damage to the tape.

19 Online resource: “Wet playing of reel tapes with Loss of Lubricant-A guest article by Marie O'Connell”, http:/ / bit.ly/wetPlaying (last visited on 27 April 2019)

20 Personal communication to one of the authors on 3 February 2006.

21 See "Preservation Recording, Copying, and Storage Guidelines for Audio Tape Collections" published by Lyrasis in 2008: https:/ / www.lyrasis.org/services/Documents / AudioTape-Guidelines.pdf (last visited on 25 April 2019). 
- A current outline of storage recommendations for tape can be found in [124] (Section 3.3). There are some caveats to consider when analyzing these limits and this is an area of further research as film historians are freezing film to preserve it longer.

- It is likely that tapes coated on an acetate base film do not perform as well at the lower range of the recommended $\mathrm{RH}$.

- The "do not freeze" warning about tape came from concerns over early tapes that used a variety of naturally occurring lubricants, often extracted from marine creatures. What is interesting is that some sample lubricants that Hess has in his possession appear to congeal below about $15^{\circ} \mathrm{C}$, thus these would be congealed at the minimum recommended temperature of $8^{\circ} \mathrm{C}$ recommended in [124].

- The above two sub-points suggest further research.

The reason so much effort is put in the study of magnetic tapes is, of course, the audio content. When the tape is compromised, so is our ability to access the acoustic information it carries. However, if ageing has a destructive effect on tapes integrity, so can-in principle-treatments for cleaning, recovery, and optimization. Therefore, it is legitimate to ask whether certain procedures do not cause, besides the intended rejuvenation of the tape, an alteration of the sound signal. Whether the alteration is desirable (enhanced intelligibility, richer spectrum, etc.) or undesirable (further degradation) is to be determined. To do so, it is necessary to design studies that combine chemical and audio analyses. Bressan et al. [125] presented an example of a study that aims to determine the modifications that thermal treatment induces both on magnetic tape and on the audio signal on that tape. To do so, a set of chemical analyses were conducted on a tape sample before and after thermal treatment, and audio analyses were conducted on the corresponding digitized signals. A set of audio features was selected to characterize the audio spectrum. The results obtained testing a tape that did not show any marked sign of degradation (i.e., a tape that may be labeled "in good condition") returned consistent results between the chemical and audio analyses, and did not reveal any significant differences between before and after the treatment. This is a positive result because it shows that thermal treatment, at these conditions, does not have a destructive effect on the tape or on the signal. Future work includes repeating the test on tape samples that show marked signed of degradation.

\section{Conclusions}

Audio magnetic tapes are complex and multi-component devices containing organic compounds and metal systems, which can potentially catalyze many reactions in the presence of water, light or heating.

Many common techniques for analytical chemistry have been used to identify unknown tapes and study the degradation state to prevent further degradation and individuate the best conditions for long storage. There is a rapid and continuous evolution in the instrumental equipment which allows studying materials; thus, all methods actually in use to study polymeric materials (such as neutron scattering or TEM) could be used for audio tapes, too, with the aim to better understand chemical, structural, morphological and functional aspects. The thermodynamic stability of iron oxides is sensitive to magnetization states, chemical surrounding, particles size and shapes, and defects in crystalline phases, thus forming a complicated parameter set, which represents a challenging research field with these specific devices.

An intriguing tool would be to combine destructive analyses on extracts (which can be carried out by GC-MS on very few milligrams of sample from the beginning of the tape, usually not recorded) with non-destructive approaches (such as ATR-FTIR, which could be performed continuously) and ESEM images, to build an as large as possible database, open to workers in archives interested in preserving our sounds heritage. 
Author Contributions: Conceptualization, F.B., R.B. and R.L.H.; methodology, F.B., R.B. and R.L.H.; formal analysis, R.B.; investigation, F.B., R.B., P.S. and R.L.H.; resources, R.B. and P.S.; data curation, F.B. and R.H; writing-original draft preparation, R.B. and R.L.H.; writing-review and editing, F.B., R.B., P.S. and R.L.H.; visualization, P.S. and R.L.H.; supervision, F.B.; project administration, F.B.; and funding acquisition, F.B.

Funding: This study was partially supported by the European Union's Horizon 2020 research and innovation programme under the Marie Skłodowska-Curie grant agreement No. 703937.

Conflicts of Interest: The authors declare no conflict of interest. The funders had no role in the design of the study; in the collection, analyses, or interpretation of data; in the writing of the manuscript, or in the decision to publish the results.

\section{Abbreviations}

The following abbreviations are used in this manuscript:

$\begin{array}{ll}\text { AES } & \text { Audio Engineering Society (New York, NY, USA) } \\ \text { ATR FTIR } & \text { Attenuated total reflectance Fourier transform infrared spectroscopy } \\ \text { ESEM } & \text { Environmental scanning electron microscopy } \\ \text { FT-IR } & \text { Fourier transform infrared spectroscopy } \\ \text { GC MS } & \text { Gas chromatography mass spectrometry } \\ \text { IASA } & \text { International Association of Sound and Audiovisual Archives (Amsterdam, The Netherlands) } \\ \text { LD } & \text { linear dichroism } \\ \text { NAB } & \text { National Association of Broadcasters (Washington, DC, USA) } \\ \text { NMR } & \text { Nuclear magnetic resonance } \\ \text { PEN } & \text { Polyethylene naphthalate (used as a base film) } \\ \text { PE-PU } & \text { Polyester polyurethane (used as a binder) } \\ \text { PET } & \text { Polyethylene terephthalate (common base film) } \\ \text { PM-IRLD } & \text { polarization modulation infrared linear dichroism } \\ \text { PVC } & \text { Polyvinyl chloride (historic base film) } \\ \text { RH } & \text { Relative humidity } \\ \text { SEM } & \text { Scanning electron microscopy } \\ \text { SIMS } & \text { Secondary ion mass spectrometry } \\ \text { SMPTE } & \text { Society of Motion Picture and Television Engineers (White Plains, NY, USA) } \\ \text { SPME } & \text { Solid phase micro extraction } \\ \text { Tg } & \text { Glass transition temperature } \\ \text { TGA } & \text { Thermogravimetric analysis } \\ \text { UHV } & \text { Ultra high vacuum } \\ \text { URS-FTIR } & \text { Ultra-rapid scanning spectroscopy } \\ \text { VOC } & \text { Volatile organic compounds } \\ \text { XRD } & \text { X-ray powder diffraction } \\ & \end{array}$

\section{References}

1. Engel, F. Magnetic Tape from the Early Days to the Present. J. Audio Eng. Soc. 1988, 36, 606-616.

2. Schüller, D. Preserving the Facts for the Future: Principles and Practices for the Transfer of Analog Audio Documents into the Digital Domain. J. Audio Eng. Soc. 2001, 49, 618-621.

3. Hess, R. Tape Degradation Factors and Challenges in Predicting Tape Life. ARSC J. 2008, 39, $240-274$.

4. Richardson, C.A. Solving the Sticky Shed Problem in Magnetic Recording Tapes: New Laboratory Research and Analysis Provides a Safe and Effective Remedy; Audio Engineering Society: New York, NY, USA, 2006.

5. Richardson, C. Process for Restoring Magnetic Recording tape Damaged by Sticky Shed Syndrome. U.S. Patent US6797072, 28 September 2004. 
6. Thiébaut, B. Particulate magnetic tape materials characterisation and degradation study. In Proceedings of the Association of Moving Image Archivists (AMIA) Conference, Austin, TX, USA, 30 November-1 December 2005.

7. Hollerith, H. Art of Compiling Statistics. U.S. Patent US395782A, 8 January 1884.

8. Bradshaw, R.; Schroeder, C. Fifty years of IBM innovation with information storage on magnetic tape. IBM J. Res. Dev. 2003, 47, 373-383. [CrossRef]

9. Braun, W.L. The NAB Recording and Reproducing Standards. J. Audio Eng. Soc. 1968, 16, 168-173.

10. Telemetry Group; Range Commander Council. Telemetry Standards. IRIG STANDARD 106-04; US Army: Arlington County, VA, USA, 2004.

11. Hauttekeete, L.; Evens, T.; Moor, K.D.; Schuurman, D.; Mannens, E.; de Walle, R.V. Archives in motion: Concrete steps towards the digital disclosure of audiovisual content. J. Cult. Herit. 2011, 12, 459-465. [CrossRef]

12. Casey, M. FACET (Field Audio Collection Evaluation Tool)-Procedures Manual Version 1.0; Technical Report; Indiana University: Bloomington, IN, USA, 2008.

13. Cassidy, B.M.; Breitung, E.M. Magnetic Tapes, Playable or Not? Against Grain 2015, 27, 1. [CrossRef]

14. Casey, M. Why media preservation can't wait: The gathering storm. IASA J. 2015, 44, 14-22.

15. Allen-Robertson, J. The materiality of digital media: The hard disk drive, phonograph, magnetic tape and optical media in technical close-up. New Media Soc. 2017, 19, 455-470. [CrossRef]

16. Heller, M.C. Orpheus unglued: sticky shed syndrome and tape's archival anxieties. Sound Stud. 2017, 3, 64-70. [CrossRef]

17. Green, C.V. Chemical Analysis of Magnetic Recording Tape. J. Audio Eng. Soc. 1960, 8, 156-158.

18. Scheiman, J.; Schwartz, R. An Old-School Tape Evaluator. U.S. Patent US3359783, 1967.

19. Cinadr, B. Details on Coating Systems. U.S. Patent US3650828, 1972.

20. Kaempf, G.; Loewer, H.; Witman, M. Polymers as substrates and media for data storage. Polym. Eng. Sci. 1987, 27, 1421-1425.

21. Kim, K.; Farkas, J.; Hasman, D.; Miller, T.; Zellia, J.; Jacobs, P. Recent developments in binder design for advanced media. J. Magn. Magn. Mater. 1999, 193, 265-275. [CrossRef]

22. Yilgör, E.; Yurtsever, E.; Yilgör, I. Hydrogen bonding and polyurethane morphology. II. Spectroscopic, thermal and crystallization behavior of polyether blends with 1,3-dimethylurea and a model urethane compound. Polymer 2002, 43, 6561-6568. [CrossRef]

23. Yilgor, I.; Yilgor, E.; Guler, I.G.; Ward, T.C.; Wilkes, G.L. FTIR investigation of the influence of diisocyanate symmetry on the morphology development in model segmented polyurethanes. Polymer 2006, 47, 4105-4114. [CrossRef]

24. Garrett, J.T.; Xu, R.; Cho, J.; Runt, J. Phase separation of diamine chain-extended poly(urethane) copolymers: FTIR spectroscopy and phase transitions. Polymer 2003, 44, 2711-2719. [CrossRef]

25. Tu, R.S. Polymers in Information Storage Technology; Chapter Mechanism of Chemical Reactions Involved in Magnetic Coatings; Springer: New York, NY, USA, 1989; pp. 345-350.

26. Nakamae, K.; Tanigawa, S.; Sumiya, K.; Matsumoto, T. Polymers in Information Storage Technology; Chapter Role of Active Functional Groups and Conformation of Adsorbed Polymers in the Dispersibility of Magnetic Particles; Springer: New York, NY, USA, 1989; pp. 407-420.

27. Boynton, G.; Ingersoll, H. Magnetic Tape Binder from a Polyurethane, a Polyol and an Isocyanate. U.S. Patent US3926826, 16 Decmeber 1975.

28. Deffeyes, R. Magnetic Tape. U.S. Patent US4020227, 1976.

29. Johnson, R. Process of Making High-Temperature Magnetic Tape. U.S. Patent US4189514, 19 February 1980.

30. Ninomiya, Y.; Hashimoto, A. Magnetic Recording Medium. U.S. Patent US4529661, 1985.

31. Sharrock, M.P. Particulate Magnetic Recording Media: A Review. IEEE Trans. Magn. 1989, 25, 4374-4389. [CrossRef]

32. Potgiesser, J.A.L.; Koorneef, J. Mechanical wear and degeneration of the magnetic properties of magnetic heads caused by the tape. Radio Electron. Eng. 1974, 44, 313-318. [CrossRef] 
33. Hisano, S.; Saito, K. Research and development of metal powder for magnetic recording. J. Magn. Magn. Mater. 1998, 190, 371-381. [CrossRef]

34. Cornell, R.M.; Schwertmann, U. The Iron Oxides: Structure, Properties, Reactions, Occurrences and Uses; Wiley: Hoboken, NJ, USA, 2004.

35. Guo, H.; Barnard, A.S. Iron Oxides: From Nature to Applications; Chapter Thermodynamics of Iron Oxides and Oxyhydroxides in Different Environments; Wiley: Hoboken, NJ, USA, 2016; pp. 269-292.

36. Vereda, F. Iron Oxides: From Nature to Applications; Chapter Introduction to Standard Spectroscopic Methods: XRD, IR/Raman, and Mössbauer; Wiley: Hoboken, NJ, USA, 2016; pp. 295-324.

37. Faivre, D. (Ed.) Iron Oxides: From Nature to Applications; Wiley: Hoboken, NJ, USA, 2016.

38. Dismukes, J.P.; Martin, D.F.; Ekstrom, L.; Wang, C.C.; Coutts, M.D. Ferromagnetic Chromium Dioxide for Magnetic Tape. Prod. R D 1971, 10,319-329. [CrossRef]

39. Nishida, Y.; Hisamichi, Y.; Kondo, H. Behavior of perfluoropolyether in particulate magnetic recording media. IEEE Trans. Magn. 1996, 32, 3738-3740. [CrossRef]

40. Bhushan, B.; Hahn, F.W. Stains on magnetic tape heads. Wear 1995, 184, 193-202. [CrossRef]

41. Bhushan, B.; Patton, S.T. Tribology in ultra-high density tape drive systems: State of the art and future challenges. IEEE Trans. Magn. 1998, 34, 1883-1888. [CrossRef]

42. Bhushan, B. Tribology and Mechanics of Magnetic Storage Devices; Springer: New York, NY, USA, 1996.

43. Bhushan, B.; Cichomski, M.; Tao, Z.; T. Tran, N.; Ethen, T.; Merton, C.; Jewett, R.E. Nanotribological Characterization and Lubricant Degradation Studies of Metal-Film Magnetic Tapes Using Novel Lubricants. J. Tribol.-Trans. ASME 2007, 129, 621-627. [CrossRef]

44. van Groenou, A.B. Tribology of magnetic storage systems, a short review. J. Magn. Magn. Mater. 1991, 95, $289-312$. [CrossRef]

45. Wierenga, P.; Schaake, R. The effect of mechanical and chemical surface properties on the friction of magnetic tapes. Wear 1987, 119, 29-50. [CrossRef]

46. Raeymaekers, B.; Etsion, I.; Talke, F.E. Enhancing tribological performance of the magnetic tape/guide interface by laser surface texturing. Tribol. Lett. 2007, 27, 89. [CrossRef]

47. Bhushan, B.; Khatavkar, D.V. Role of tape abrasivity on friction, wear, staining and signal degradation in audio tapes. Wear 1995, 190, 16-27. [CrossRef]

48. Bhushan, B. (Ed.) Nanotribology and Nanomechanics. An Introduction; Springer: Berlin/Heidelberg, Germany, 2008.

49. Bhushan, B. Mechanics and Reliability of Flexible Magnetic Media; Springer: New York, NY, USA, 2012.

50. Bradshaw, R.L.; Bhushan, B. Friction in Magnetic Tapes III: Role of Chemical Properties. ASLE Trans. 1984, 27, 207-219. [CrossRef]

51. Palacio, M.; Bhushan, B. Nanotribological properties of novel lubricants for magnetic tapes. Ultramicroscopy 2009, 109, 980-990. [CrossRef]

52. Bhushan, B. Tribology and Mechanics of Magnetic Storage Devices; Chapter Interface Temperature of Sliding Surfaces; Springer Science \& Business Media: Berlin, Germany, 1996; pp. 366-411.

53. Raymond Engineering Inc. newblock OSO Head and Tape Studies; Final Report No. 705-8; Technical Report; NASA/GSFC: Washington, DC, USA, 1968.

54. Bressan, F.; Bertani, R.; Furlan, C.; Simionato, F.; Canazza, S. An ATR FTIR And ESEM Study On Magnetic Tapes For The Assessment Of The Degradation Of Historical Audio Recordings. J. Cult. Herit. 2016, 18, 313-320. [CrossRef]

55. Judge, J.; Schmidt, R.; Weiss, R.; Miller, G. Media stability and life expectancies of magnetic tape for use with IBM 3590 and digital linear tape systems. In Proceedings of the 20th IEEE/11th NASA Goddard Conference on Mass Storage Systems and Technologies (MSST 2003), San Diego, CA, USA, 7-10 April 2003.

56. Okazaki, Y.; Hara, K.; Kawashima, T.; Sato, A.; Hirano, T. Estimating the archival life of metal particulate tape. IEEE Trans. Magn. 1992, 28, 2365-2367. [CrossRef] 
57. Wheeler, J. Long-Term Storage of Videotape. SMPTE J. 1983, 92, 650-654. [CrossRef]

58. Rusch, A.; Beekman, E.; Lascaro, C. newblock Reinforced Plastic Magnetic Tapes; Technical Report 2324; Technical Report; USAEL-RDL: Kanagawa, Japan, 1963.

59. Goldade, A.; Bhushan, B. Measurement and Origin of Tape Edge Damage in a Linear Tape Drive. Tribol. Lett. 2003, 14, 167-180. [CrossRef]

60. Brokerhof, A.W.; van Zanen, B.; den Teuling, A. Fluffy Stuff: Integrated Control of Mould in Archives; Netherlands Institute for Cultural Heritage (ICN): Amsterdam, The Netherlands, 2007.

61. Florian, M.L.E. Heritage Eaters: Insects and Fungi in Heritage Collections; UBC Community and Partner Publications, James and James (Science Publishers) Ltd.: Northampton, UK, 1997. [CrossRef]

62. AES. AES Recommended Practice for Audio Preservation and Restoration-Storage of Polyester-Base Magnetic Tape; AES: New York, NY, USA, 1997.

63. Bogart, J.W.V. Magnetic Tape Storage and Handling. A Guide for Libraries and Archives; Technical Report; National Media Laboratory: New York, NY, USA, 1995.

64. Ma, Z.; Hong, Y.; Nelson, D.M.; Pichamuthu, J.E.; Leeson, C.E.; Wagner, W.R. Biodegradable Polyurethane Ureas with Variable Polyester or Polycarbonate Soft Segments: Effects of Crystallinity, Molecular Weight, and Composition on Mechanical Properties. Biomacromolecules 2011, 12, 3265-3274. [CrossRef]

65. Costa, C.Z.; Albuquerque, M.d.C.C.d.; Brum, M.C.; Castro, A.M.d. Degradação microbiológica e enzimática de polímeros: uma revisão. Química Nova 2015, 38, 259-267.

66. Lando, G.A.; Marconatto, L.; Kessler, F.; Lopes, W.; Schrank, A.; Vainstein, M.H.; Weibel, D.E. UV-Surface Treatment of Fungal Resistant Polyether Polyurethane Film-Induced Growth of Entomopathogenic Fungi. Int. J. Mol. Sci. 2017, 18, 1536. [CrossRef]

67. Schmidt, J.; Wei, R.; Oeser, T.; Dedavid e Silva, L.; Breite, D.; Schulze, A.; Zimmermann, W. Degradation of Polyester Polyurethane by Bacterial Polyester Hydrolases. Polymers 2017, 9, 65. [CrossRef] [PubMed]

68. Zafar, U.; Nzeram, P.; Langarica-Fuentes, A.; Houlden, A.; Heyworth, A.; Saiani, A.; Robson, G.D. Biodegradation of polyester polyurethane during commercial composting and analysis of associated fungal communities. Bioresour. Technol. 2014, 158, 374-377. [CrossRef] [PubMed]

69. Tian, Q.; Takács, E.; Krakovský, I.; Horváth, Z.; Rosta, L.; Almásy, L. Study on the microstructure of polyester polyurethane irradiated in air and water. Polymers 2015, 7, 1755-1766. [CrossRef]

70. Labed, V.; Obeid, H.; Ressayre, K. Effect of relative humidity and temperature on PVC degradation under gamma irradiation: Evolution of $\mathrm{HCl}$ production Yields. Radiat. Phys. Chem. 2013, 84, 26-29. [CrossRef]

71. Brown, D.W.; Lowry, R.E.; Smith, L.E. Kinetics of Hydrolytic Aging of Polyester Urethane Elastomers. Macromolecules 1980, 13, 248-252. [CrossRef]

72. Wilhelm, C.; Gardette, J.L. Infrared analysis of the photochemical behaviour of segmented polyurethanes: 1 Aliphatic poly(ester-urethane). Polymer 1997, 38, 4019-4031. [CrossRef]

73. Tosh, B. Thermal analysis of cellulose esters prepared from different molecular weight fractions of high a-cellulose pulp. Indian J. Chem. Technol. 2011, 18, 451-457.

74. Edge, M.; Mohammadian, M.; Hayes, M.; Allen, N.S.; Brems, K.; Jones, K. Aspects of Polyester Degradation: Motion Picture Film and Videotape Materials. J. Imaging Sci. Technol. 1992, 36, 13-20.

75. Pirzadeh, E.; Zadhoush, A.; Haghighat, M. Hydrolytic and thermal degradation of PET fibers and PET granule: The effects of crystallization, temperature, and humidity. J. Appl. Polym. Sci. 2007, 106, 1544-1549. [CrossRef]

76. Vos, M.; Ashton, G.; Vanbogart, J.; Ensminger, R. Heat and moisture diffusion in magnetic tape packs. IEEE Trans. Magn. 1994, 30, 237-242. [CrossRef]

77. Pellerin, C.; Pézolet, M.; Griffiths, P.R. Time-Resolved Infrared Spectroscopic Studies of Poly(ethylene terephthalate) Deformation. Macromolecules 2006, 39, 6546-6551. [CrossRef]

78. Bertram, H.N.; Cuddihy, E.F. Kinetics of the Humid Aging of Magnetic Recording Tape. IEEE Trans. Magn. 1982, 27, 4388-4395. [CrossRef]

79. Cuddihy, E. Hygroscopic Properties of Magnetic Recording Tape. IEEE Trans. Magn. 1976, MAG-12, 126-135. 
80. Cuddihy, E. Aging of Magnetic Recording Tape. IEEE Trans. Magn. 1980, MAG-16, 558-568.

81. Norris, S. Effects of Desiccation on Degraded Binder Extraction in Magnetic Audio Tape. ARSC J. $2010,41$.

82. Cuddihy, E. Storage, Preservation, and Recovery of Magnetic Recording Tape; Technical Report; NASA: Washington, DC, USA, 1994.

83. Edge, M.; Allen, N.; Chen, W.; Horie, C. Degradation of magnetic tape: Binder oxidation studies. Eur. Polym. J. 1993, 29, 1031-1035. [CrossRef]

84. Edge, M.; Allen, N.; Hayes, M.; Jewitt, T.; Brems, K.; Horie, V. Degradation of magnetic tape: Support and binder stability. Polym. Degrad. Stabil. 1993, 39, 207-214. [CrossRef]

85. Nakamae, K.; Yamaguchi, K.; Asaoka, S.; Karube, Y.; Sudaryanto. Lifetime expectancy of polyurethane binder as magnetic recording media. Int. J. Adhes. Adhes. 1996, 16, 277-283. [CrossRef]

86. Hahn, F. Head wear as a function of isolated asperities on the surface of magnetic tape. IEEE Trans. Magn. 1984, 20,918-920. [CrossRef]

87. Salazar, M.R.; Lightfoot, J.M.; Russell, B.G.; Rodin, W.A.; McCarty, M.; Wrobleski, D.A.; Orler, E.B.; Spieker, D.A.; Assink, R.A.; Pack, R.T. Degradation of a poly(ester urethane) elastomer. III. Estane 5703 hydrolysis: Experiments and modeling. J. Polym. Sci. Part A Polym. Chem. 2003, 41, 1136-1151. [CrossRef]

88. Thompson, D.G.; Osborn, J.C.; Kober, E.M.; Schoonover, J.R. Effects of hydrolysis-induced molecular weight changes on the phase separation of a polyester polyurethane. Polym. Degrad. Stabil. 2006, 91, 3360-3370. [CrossRef]

89. Pack, R.; Hanson, D.; Redondo, A. Chemical Kinetics of Estane Aging in PBX; Technical Report; UNT Libraries Government Documents Department: Denton, TX, USA, 1997.

90. Bradshaw, R.; Falcone, S. Polymers in Information Storage Technology; Chapter Polyester-Polyurethane Interactions with Chromium Dioxide; Springer: New York, NY, USA, 1989; pp. 385-405.

91. Hadad, A.S. An empirical approach to predicting long term behavior of metal particle based recording media. In Proceedings of the Conference on Mass Storage Systems and Technologies for Space and Earth Science Applications, Greenbelt, MD, USA, 23-25 July 1991.

92. Djalali, A.; Seng, D.; Glatfelter, W.; Lambropoulos, H.; Judge, J.S.; Speliotis, D.E. Study of the Stability of Metal Particle Data Recording Tapes. J. Electrochem. Soc. 1991, 138, 2504-2509. [CrossRef]

93. Swaddle, T.W.; Oltmann, P. Kinetics of the magnetite-maghemite-hematite transformation, with special reference to hydrothermal systems. Can. J. Chem. 1980, 58, 1763-1772. [CrossRef]

94. Dee, R.H. Magnetic Tape for Data Storage: An Enduring Technology. Proc. IEEE 2008, 96, 1775-1785. [CrossRef]

95. Mercer, T.; Bissell, P.; Tatarasanu, I. Effects of structure on noise in very thin particulate data storage media. J. Magn. Magn. Mater. 2007, 316, 199-202. [CrossRef]

96. Nishio, H.; Yamamoto, H. Long-Term Magnetization Stability of Data Storage Tape Prepared from Ultrafine Metal Particles. IEEE Trans. Magn. 2010, 46, 3747-3751. [CrossRef]

97. Nishio, H.; Yamamoto, H. Temperature dependence of long-term magnetization stability for data storage tapes prepared from ultrafine particles. Phys. Procedia 2011, 16, 58-62. [CrossRef]

98. Shimizu, O.; Murata, Y.; Kurihashi, Y.; Harasawa, T.; Asai, M.; Sueki, M.; Noguchi, H. Long-term Archival Stability of Barium Ferrite Magnetic Tape. J. Magn. Soc. Jpn. 2012, 36, 1-4. [CrossRef]

99. Bowner, T.; Hull, G.; Plitz, I. Polymers in Information Storage Technology; Chapter Characterization and Hydrolysis of Magnetic Tapes; Springer: New York, NY, USA, 1989; pp. 331-344.

100. Bottjer, W.; Ingersoll, H. Stabilized Ferromagnetic Chromium Dioxide. U.S. Patent US3512930, 19 May 1969.

101. Grlesser, H.J. Polymers in Information Storage Technology; Chapter Plasma Polymer Films for Corrosion Protection of Cobalt-Nickel 80:20 Magnetic Thin Films; Springer: New York, NY, USA, 1989; pp. 351-372.

102. Andanson, J.M.; Kazarian, S. In situ ATR-FTIR Spectroscopy of Poly(ethylene terephthalate) Subjected to High-Temperature Methanol. Macromol. Symp. 2008, 265, 195-204. [CrossRef]

103. Gómez-Sánchez, E.; Simon, S.; Koch, L.C.; Wiedmann, A.; Weber, T.; Mengel, M. ATR/FT-IR spectroscopy for the characterisation of magnetic tape materials. ePRESERVATIONScience 2011, 8, 2-9. 
104. Hobaica, S. Analysis of audio magnetic tapes with sticky shed syndrome by ATR-FTIR. J. Appl. Polym. Sci. 2013, 128, 1962-1973. [CrossRef]

105. Cassidy, B.M.; Lu, Z.; Fuenffinger, N.C.; Skelton, S.M.; Bringley, E.J.; Nguyen, L.; Myrick, M.L.; Breitung, E.M.; Morgan, S.L. Minimally Invasive Identification of Degraded Polyester-Urethane Magnetic Tape Using Attenuated Total Reflection Fourier Transform Infrared Spectroscopy and Multivariate Statistics. Anal. Chem. 2015, 87, 9265-9272. [CrossRef]

106. de Faria, D.; Silva, S.V.; de Oliveira, M.T. Raman microspectroscopy of some iron oxides and oxyhydroxides. J. Raman Spectrosc. 1997, 28, 873-878. [CrossRef]

107. Thiebaut, B.; Lattuati-Derieux, A.; Hocevar, M.; Vilmont, L.B. Application of headspace SPME-GC-MS in characterisation of odorous volatile organic compounds emitted from magnetic tape coatings based on poly(urethane-ester) after natural and artificial ageing. Polym. Test. 2007, 26, 243-256. [CrossRef]

108. Thiébaut, B.; Vilmont, L.B.; Lavédrine, B. Characterization of U-matic videotape deterioration by size exclusion chromatography and pyrolysis gas chromatography/mass spectrometry and the role of adipic acid. J. Cult. Herit. 2009, 10, 183-197. [CrossRef]

109. Bigourdan, J.L. Stability of Acetate Film Base: Accelerated-Aging Data Revisited. J. Imaging Sci. Technol. 2006, 50, 494-501. [CrossRef]

110. Bressan, F.; Bertani, R. Reproducing a detection test for magnetic tapes degradation: Acetone extraction test. In Proceedings of the 5th International Multidisciplinary Scientific Conference on Social Sciences \& Arts SGEM2018, Spa, Bulgaria, 24 August-2 September 2018; pp. 437-445.

111. Bigourdan, J.; Reilly, J.M.; Santoro, K.; Salesin, G. The Preservation of Magnetic Tape Collections: A Perspective; Technical Report NEH GRANT PA-50123-03; Image Permanence Institute, Rochester Institute of Technology: Rochester, NY, USA, 2006.

112. Bressan, F.; Canazza, S.; Bertani, R. Honey, I burnt the tapes! A study on thermal treatment for the recovery of magnetic tapes affected by Sticky Shed Syndrome. IASA J. 2015, 44, 53-64.

113. Davis, A.R.; Monroe, E.; France, F.G. Understanding Magnetic Tape Degradation by Polymeric and Material Testing. In Proceedings of the Audio Engineering Society Conference: 2018 AES International Conference on Audio Archiving, Preservation and Restoration, New York, NY, USA, 28-30 June 2018.

114. ISO/TC 42. Imaging Materials_Processed Films_Method for Determining Lubrication; Reference ISO 18904:2000; International Organization for Standardization (ISO): Geneva, Switzerland, 2000.

115. Tseng, H.; Kolycheck, E. Polymers in Information Storage Technology; Chapter Dynamic Mechanical Behavior of Thermoplastic Polyurethane in Magnetic Coatings; Springer: New York, NY, USA, 1989; pp. $373-383$.

116. Weick, B.L. Correlations between creep, shrinkage, and dynamic mechanical characteristics of magnetic tape materials. J. Appl. Polym. Sci. 2011, 120, 226-241. [CrossRef]

117. Mitin, D.; Grobis, M.; Albrecht, M. Scanning magnetoresistive microscopy: An advanced characterization tool for magnetic nanosystems. Rev. Sci. Instrum. 2016, 87. [CrossRef]

118. Hempstock, M.; Sullivan, J. A study of the mechanical and magnetic performance of metal evaporated tape. J. Magn. Magn. Mater. 1996, 155, 323-328. [CrossRef]

119. Medeiros, D.; Curtis, J.L.S.; Parry, R.; Underwood, J. Restored Magnetic Recording Media and Method of Producing Same. U.S. Patent 5,236,790, 17 August 1993.

120. Richardson, C.A. The New "Non-Baking" Cure for Sticky Shed Tapes: How Forensic Chemistry Saved the Annapolis Sounds Masters. ARSC J. 2013, 44, 217-248.

121. Hess, R.; Iraci, J.; Flak, K. The digitization of audio tapes. Techn. Bull. 2012, 30, 44.

122. Dekant, W.; Klaunig, J.E. Toxicology of decamethylcyclopentasiloxane (D5). Regul. Toxicol. Pharmacol. 2016, 74, S67-S76. Toxicity and Human Health Risk Assessment of Decamethylcyclopentasiloxane (D5). [CrossRef] [PubMed]

123. Ikonomov, N. Preservation and Digital Restoration of Audio Archives. In Review of the National Center for Digitization; Faculty of Mathematics: Belgrade, Serbia, 2003; pp. 40-45. 
124. IASA-TC 05. Handling and Storage of Audio and Video Carriers; IASA Technical Committee: Springfield, IL, USA, 2014.

125. Bressan, F.; Rodà, A.; Bertani, R. The impact of thermal treatment on magnetic tapes: An exploratory study combining chemical analyses and audio features. In Proceedings of the 2018 AES International Conference on Audio Archiving, Preservation \& Restoration, New York, NY, USA, 28-30 June 2018.

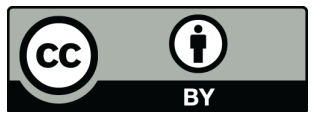

(C) 2019 by the authors. Licensee MDPI, Basel, Switzerland. This article is an open access article distributed under the terms and conditions of the Creative Commons Attribution (CC BY) license (http:/ / creativecommons.org/licenses/by/4.0/). 